\title{
Genetically encoded stealth nanoparticles of a zwitterionic polypeptide-paclitaxel conjugate have a wider therapeutic window than Abraxane in multiple tumor models
}

Samagya Banskota ${ }^{1 \dagger}$, Soumen Saha1 , Jayanta Bhattacharya ${ }^{2}$, Nadia Kirmani ${ }^{3}$, Parisa Yousefpour ${ }^{19}$, Michael Dzuricky ${ }^{1}$, Nikita Zakharov ${ }^{1}$, Xinghai Li ${ }^{1}$, Ivan Spasojevic ${ }^{4}$, Kenneth Young ${ }^{5}$, and Ashutosh Chilkoti $^{1}$

\section{Affiliations}

${ }^{1}$ Department of Biomedical Engineering, Pratt School of Engineering, Duke University, Durham, NC 27708, USA

${ }^{2}$ Center for Biomedical Engineering, Indian Institute of Technology Delhi; Hauz Khas, New Delhi, 110016, India

${ }^{3}$ Department of Biology, Trinity College of Arts and Sciences, Duke University, Durham, NC 27708, USA ${ }^{4}$ Department of Medicine, Pharmaceutical Research PK/PD Core Laboratory, Duke University Medical Center, Durham, NC 27710, USA

${ }^{5}$ Department of Radiation Oncology, Duke University Medical Center, Durham, NC 27710, USA

${ }^{*}$ Corresponding Author

Email: chilkoti@duke.edu

tPresent Address:

Merkin Institute of Transformative Technologies in Healthcare, Broad Institute of Harvard and MIT, Cambridge, MA, USA.

Department of Chemistry and Chemical Biology, Harvard University, Cambridge, MA, USA.

Howard Hughes Medical Institute, Harvard University, Cambridge, MA, USA

"Present Address:

Koch Institute for Integrative Cancer Research, Massachusetts Institute of Technology, Cambridge, USA

\section{Supplementary Information:}

Fig. S1. Characterization of ZIPP-DAD and ELP-DAD.

Fig. S2. Characterization of ZIPP-PTX and ELP-PTX micelles.

Fig. S3. In vitro testing of ZIPP-PTX and ELP-PTX micelles.

Fig. S4. Dose-escalation study.

Fig. S5. Pharmacokinetics and biodistribution of PTX micelles.

Fig. S6. Change in body weight of tumor bearing mice after treatment.

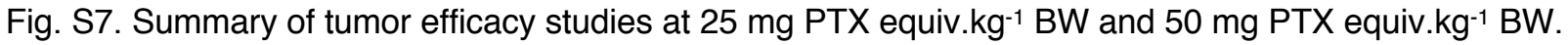

Fig. S8. Tumor response data for ZIPP and ELP without paclitaxel in subcutaneous HT-29 colon cancer xenograft model.

Fig. S9. Standard curves used across various studies.

Fig. S10: Stability Data for ZIPP-PTX and ELP-PTX.

Fig. S11: Stability Data for ZIPP-DAD and ELP-DAD.

Table S1. Amino acid sequence of ELP and ZIPP used for paclitaxel delivery.

Table S2. Hydrodynamic radius of ZIPP and ELP nanoparticles formed after Cy5 conjugation.

Table S3. Pharmacokinetic parameters from various PK studies

Table S4. Summary of tumor response for PC3 and HT-29 xenograft models.

Table S5. Summary of papers reporting paclitaxel nanoformulations along with in vivo studies after 2005 
A

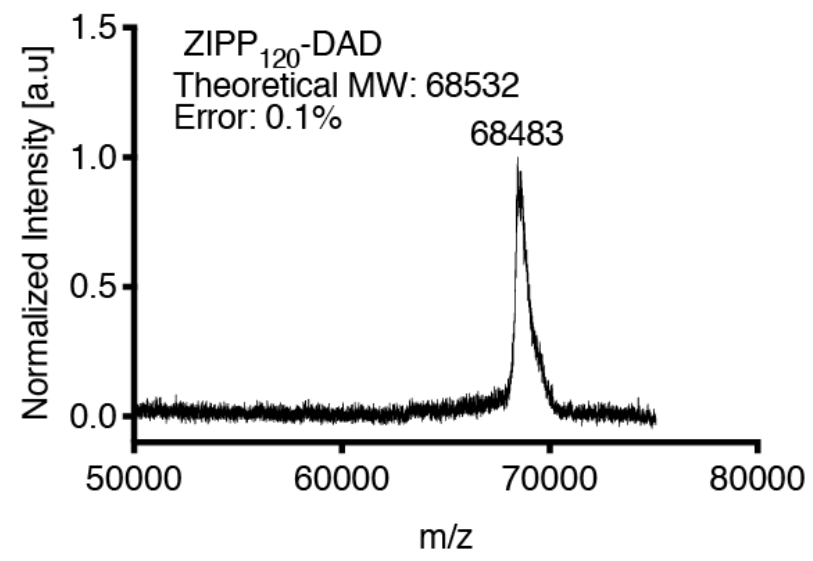

B

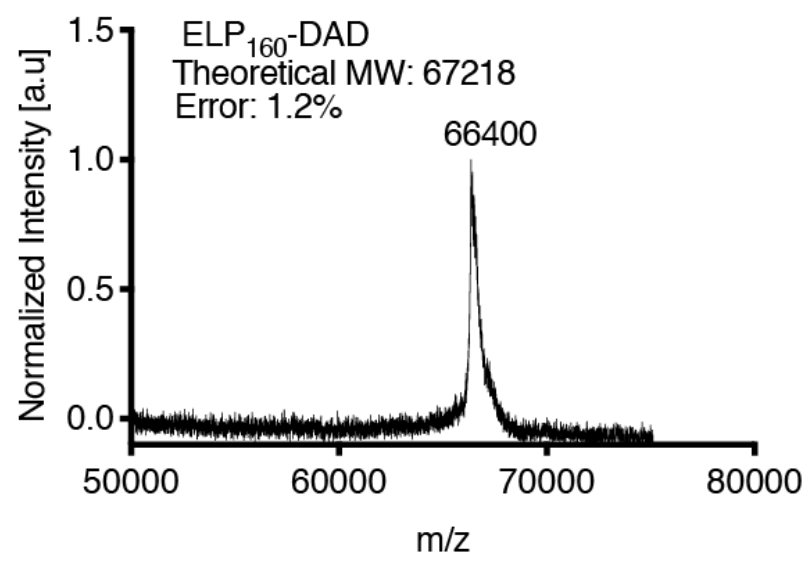

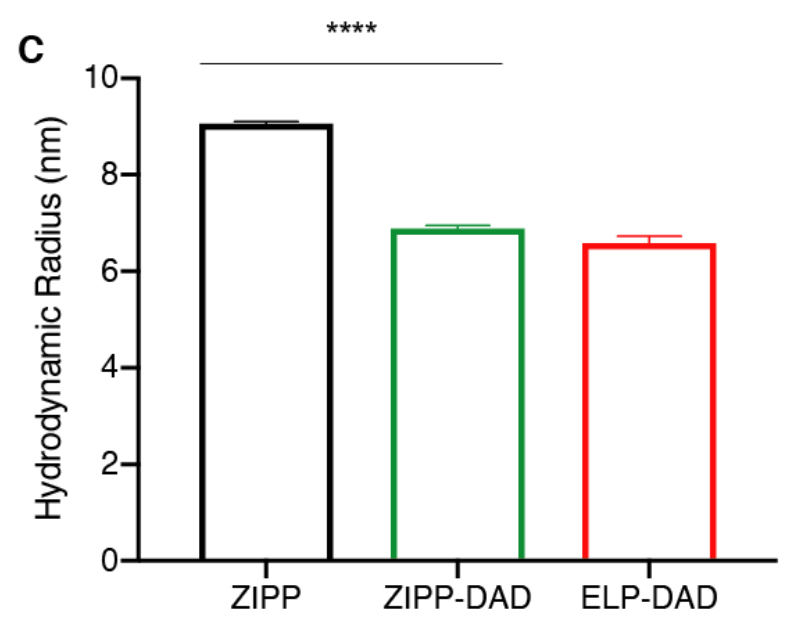

Fig. S1. Characterization of ZIPP-DAD and ELP-DAD.

MALDI-TOF-MS spectra of ZIPP-DAD (A) and ELP-DAD (B). C. Hydrodynamic radius ( $\left.R_{h}\right)$ of ZIPP, ZIPP-DAD, and ELP-DAD shows that incorporation of a C-terminal cysteine rich drug attachment domain (DAD) significantly reduces the extended conformation of the ZIPP. ( ${ }^{* * *} \mathrm{P}<0.0001$, one-way ANOVA, Tukey's post-hoc test). 
A

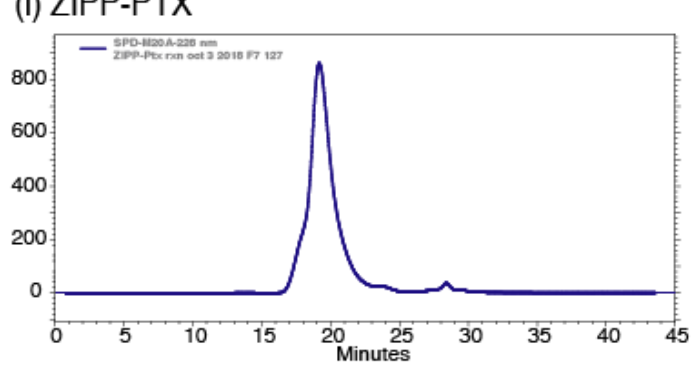

B (i) ZIPP-PTX

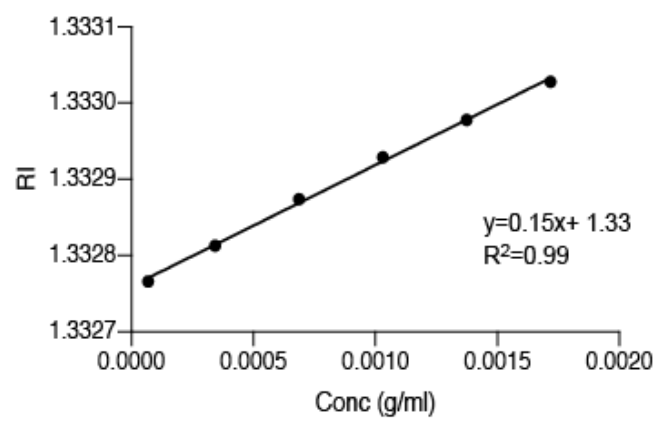

C

(i) ZIPP-PTX

$\times 10^{7}$

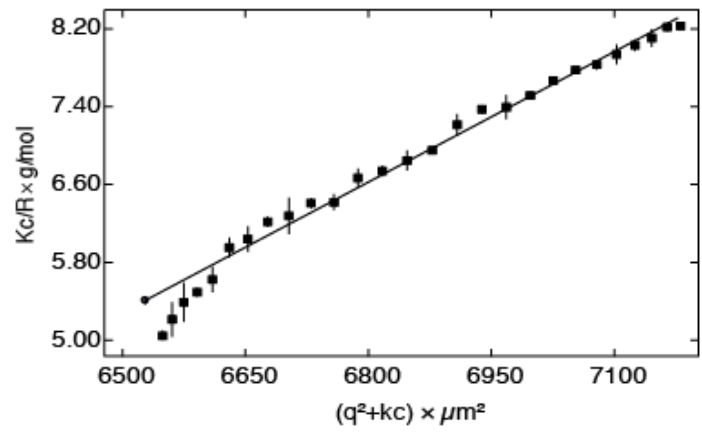

D

(i) ZIPP-PTX

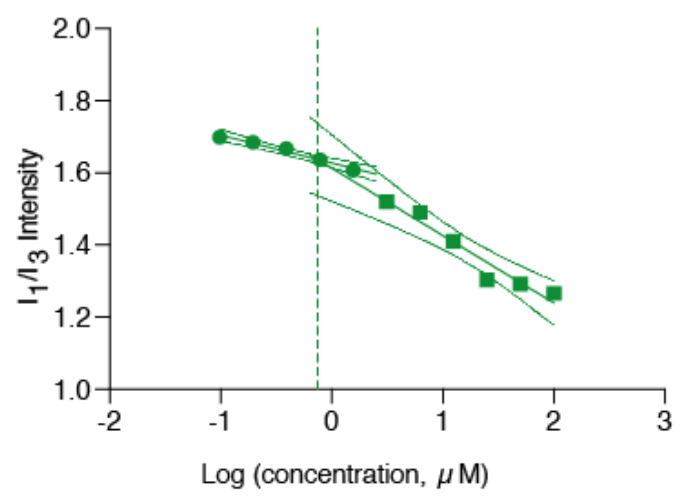

(ii) ELP-PTX

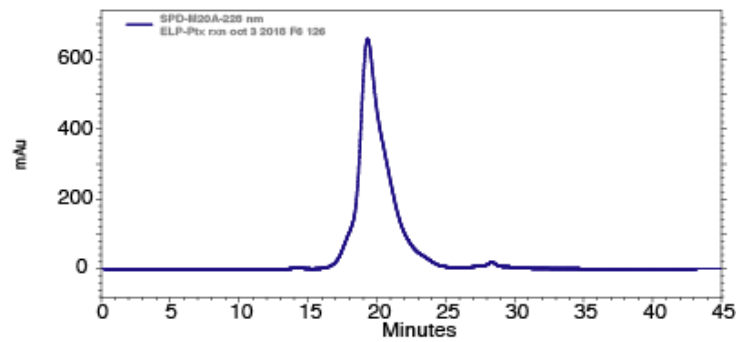

(ii) ELP-PTX

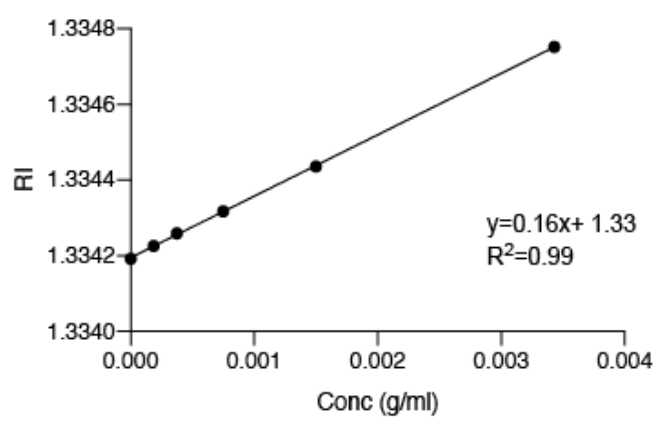

(ii) ELP-PTX

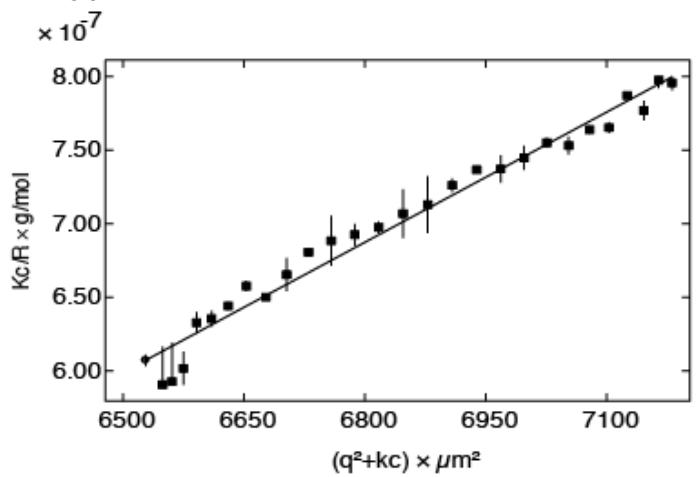

(ii) ELP-PTX

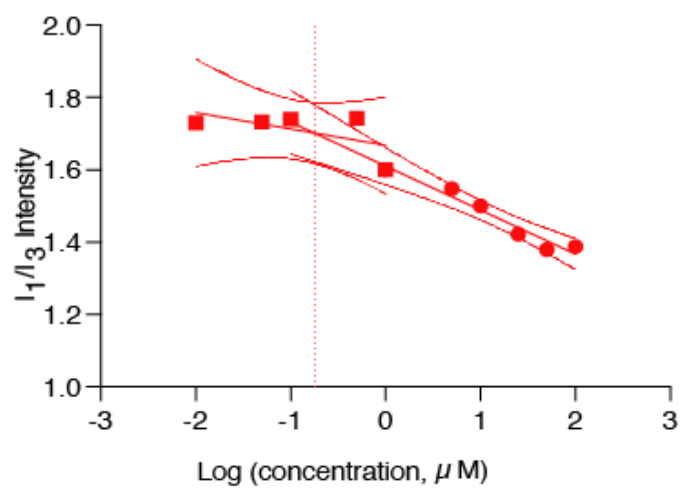

Fig. S2. Characterization of ZIPP-PTX and ELP-PTX micelles.

A. Assessment of purity after paclitaxel (PTX) conjugation to ELP_DAD (i) and ZIPP-DAD (ii) by SEC-HPLC. In the HPLC trace, the first peak at 17 min corresponds to the conjugates and the second peak at 29 min corresponds to free PTX. Purity of the conjugates was quantified by calculating the integrated area under the peak at $228 \mathrm{~nm}$, corresponding the absorbance of PTX. The average purity of the conjugates was greater than $96 \%$. B. The refractive index (RI) as a function of concentration for ZIPP-PTX (i) and ELP-PTX (ii). The differential refractive index (dn/dc) is the slope of the linear fit of the data. C. Partial Zimm plot ( $\mathrm{Kc} / \mathrm{R}$ vs $\left.\mathrm{q}^{2}\right)$ for ZIPP-PTX (i) and ELP-PTX micelles (ii). D. Critical micelle concentration (CMC) of ZIPP-PTX (i) and ELP-PTX (ii). The pyrene fluorescence was measured as a function of ZIPP or ELP concentration in PBS. The solid lines represent the best linear fit of the two regions of the data. The dashed vertical line represents the intersection point of the two linear fits, and is defined as the CMC. 
A

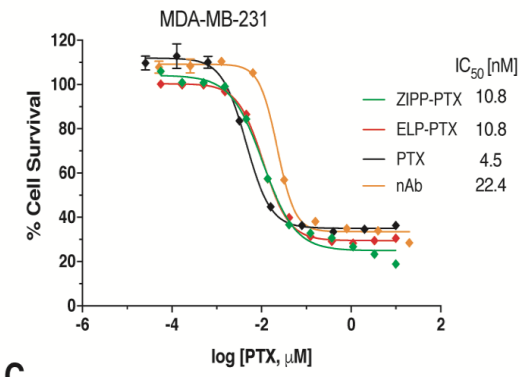

C

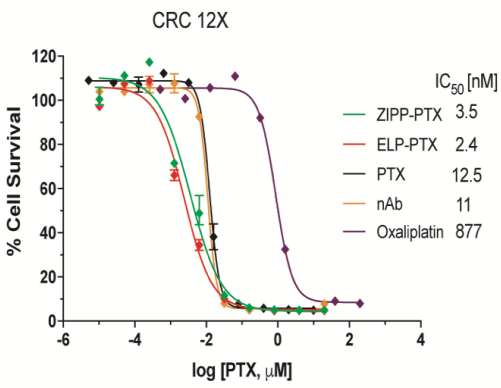

E

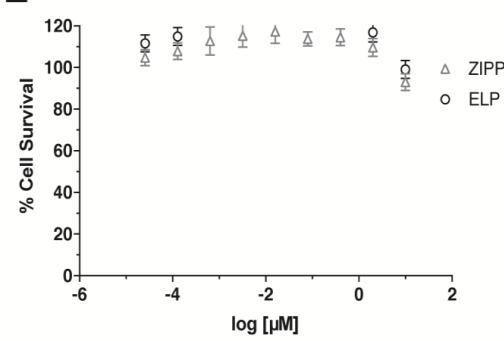

B
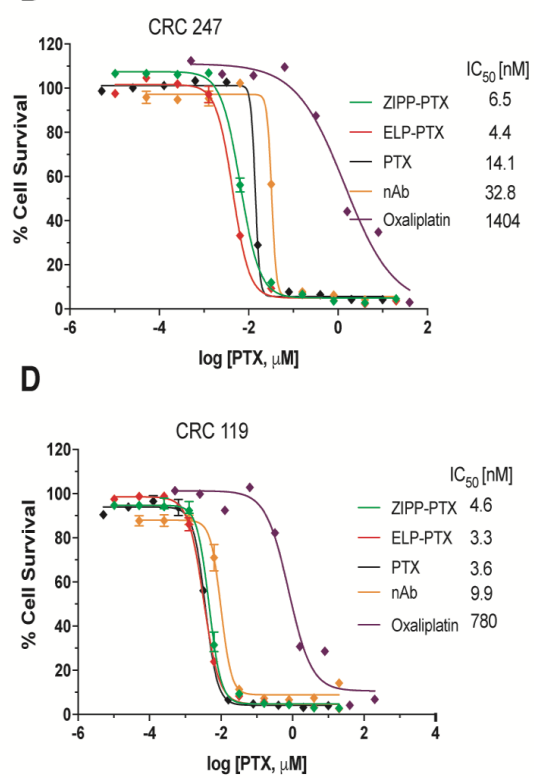

$\mathbf{F}$

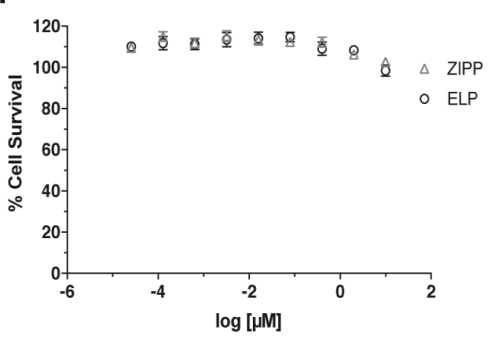

Nanoparticles
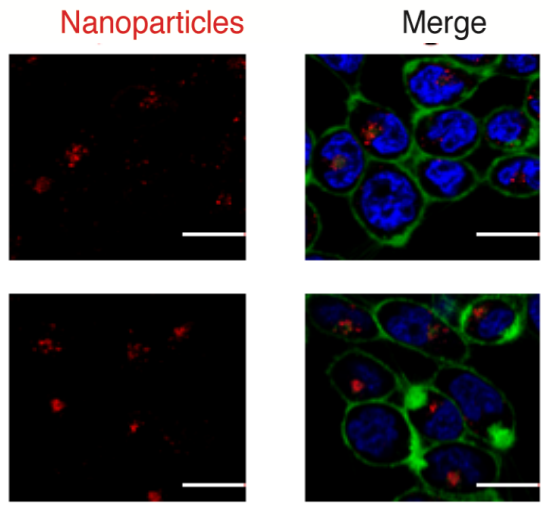

(ii)

ZIPP-PTX Cy5.5

$4 \mathrm{~h}$
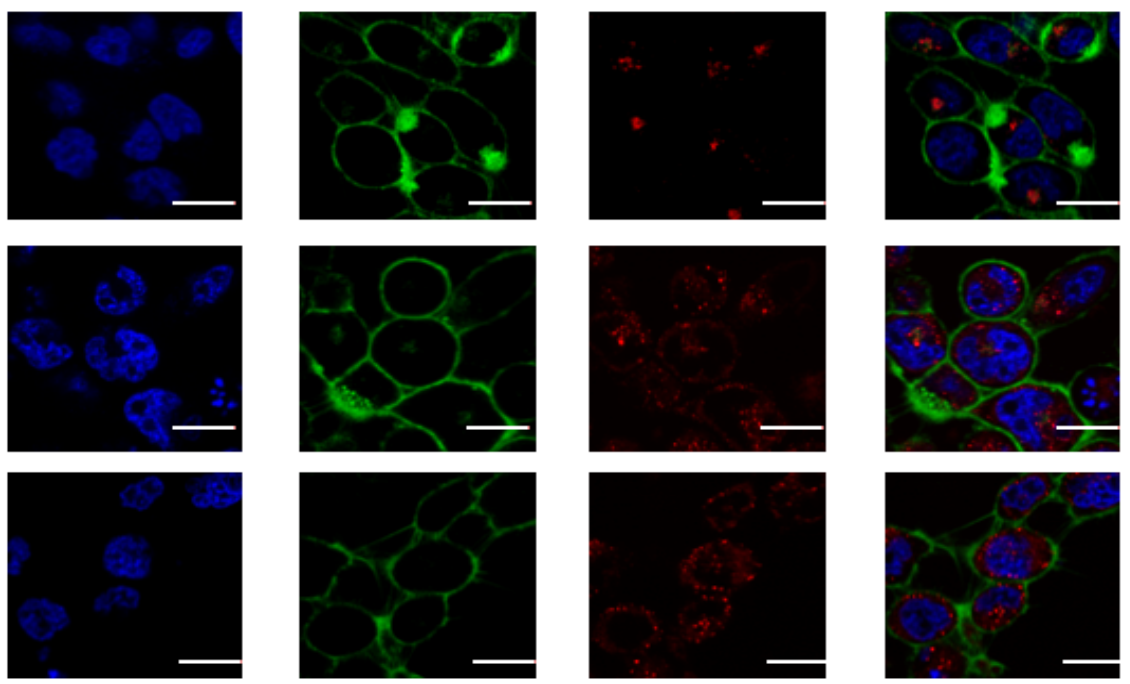

Fig. S3. In vitro testing of ZIPP-PTX and ELP-PTX micelles.

Cell viability assay for MDA-MB-231, a triple negative breast cancer cell line (A) and three human patient-derived colon cancer cell lines (B-D) treated with ZIPP-PTX, ELP-PTX, Abraxane (nAb) and free PTX. Cell viability data for 
ELP and ZIPP without PTX conjugation in (E) PC-3, a prostate cancer cell line, and (F) HT-29, a colon cancer cell line. Free polypeptide has no effect on cell viability. G. Cellular uptake of Cy 5.5 labeled ZIPP-PTX and ELP-PTX micelles. PC3 cells were treated with either Cy5.5 labeled ZIPP-PTX or ELP-PTX micelles (red) for $4 \mathrm{~h}$ (i) or $24 \mathrm{~h}$ (ii) at $37{ }^{\circ} \mathrm{C}$. Following incubation, cells were treated with CellMask ${ }^{\mathrm{TM}}$ Green to stain the plasma membrane and Hoescht 33342 (blue) to visualize nuclei and imaged with confocal fluorescence microscopy. Scale bar is $20 \mu \mathrm{m}$.
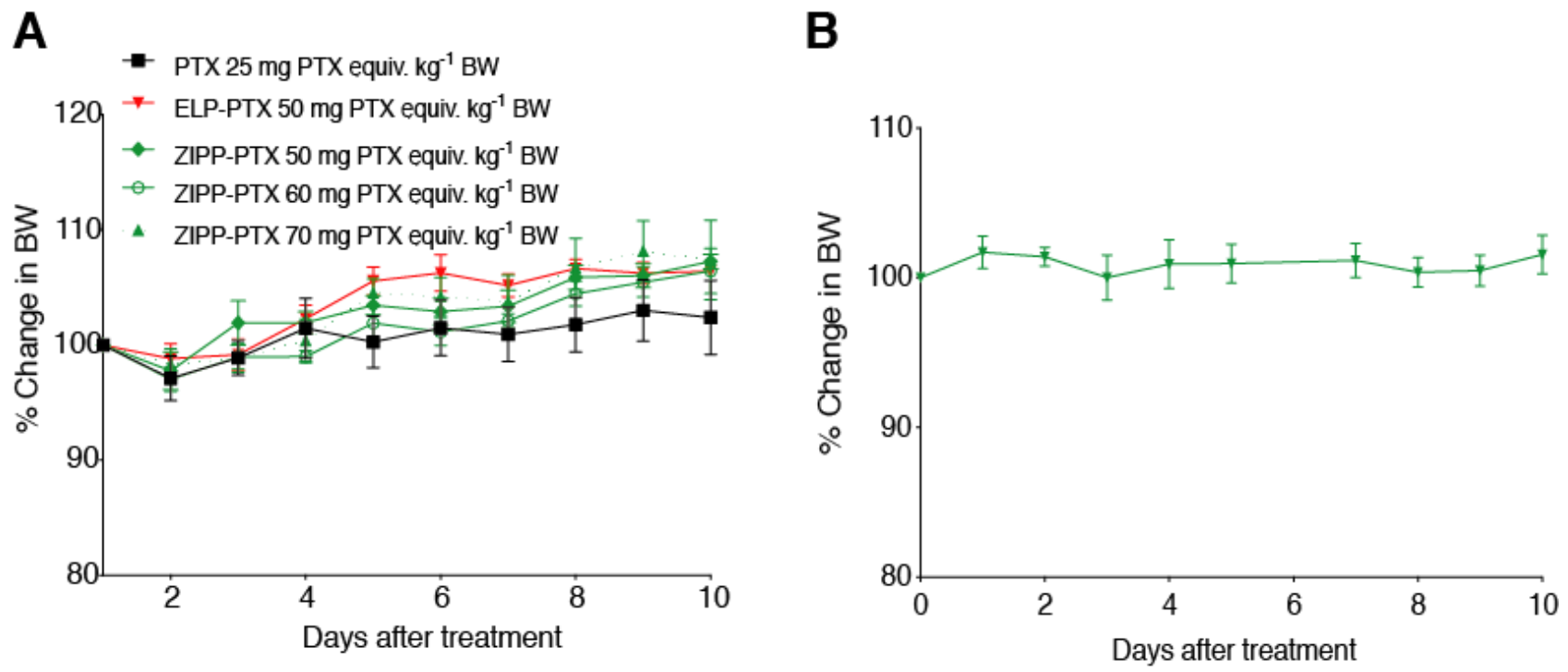

Fig. S4. Dose-escalation study.

A. A dose-escalation study of ZIPP-PTX in healthy nude mice along with controls - free PTX (at its MTD) and ELP-PTX (at its maximum injectable dose). Drug was administered by intravenous infusion on day 0 . Data represent mean \pm SEM $(n=3)$. B. ZIPP unimer was administered at a protein concentration equivalent to the ZIPP concentration in a $70 \mathrm{mg}$ PTX equiv. $\mathrm{kg}^{-1} \mathrm{BW}$ dose on day 0 . Body weight was tracked over 10 days to assess any toxicity associated with the ZIPP. Data shows that ZIPP unimer is well tolerated with less than $3 \%$ BW loss. Data represent mean \pm SEM $(n=4)$. 

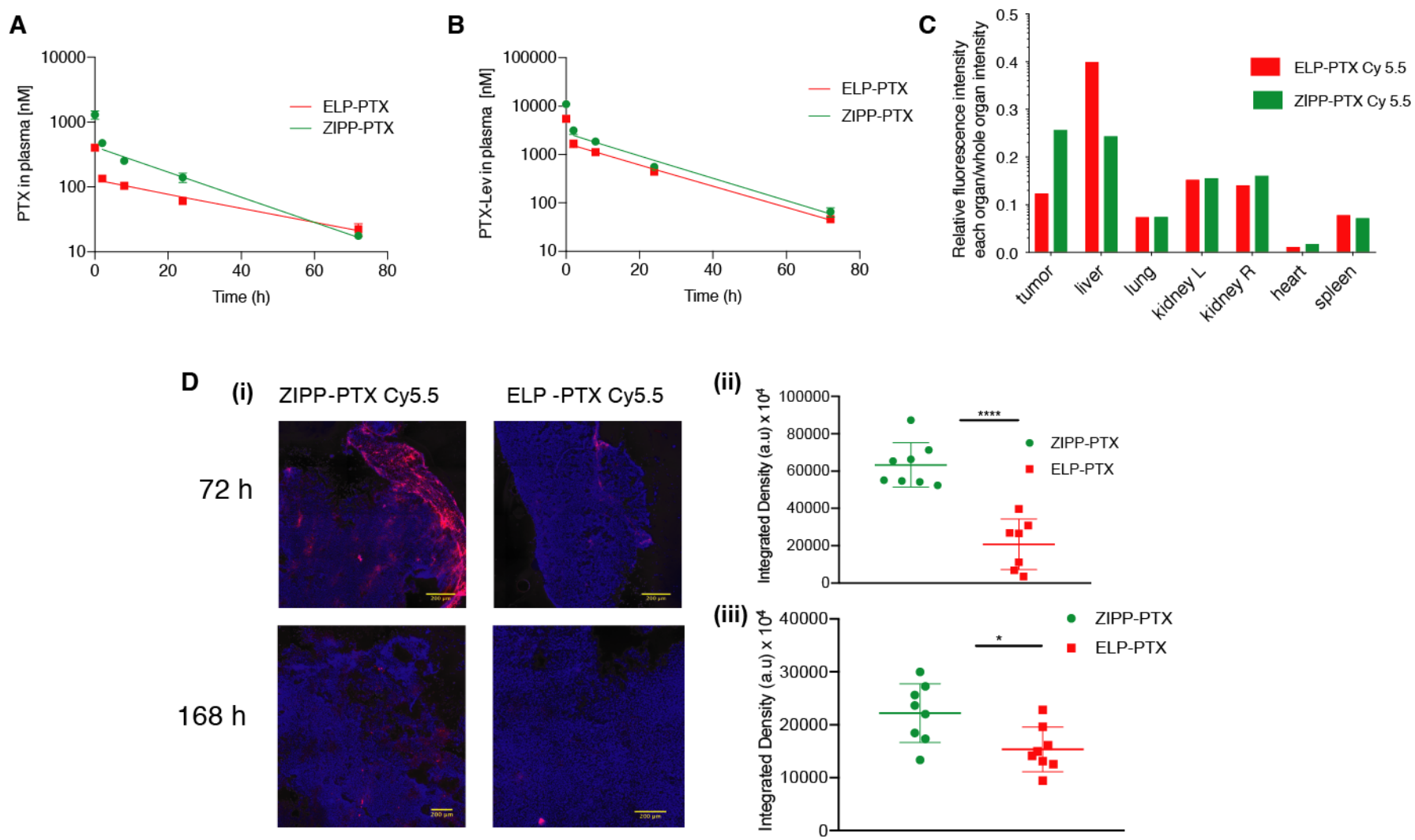

Fig. S5. Pharmacokinetics and biodistribution of PTX micelles.

Pharmacokinetic (PK) study of ZIPP-PTX and ELP-PTX micelles. ZIPP-PTX micelles and ELP-PTX micelles were administered via tail vein infusion in athymic nude mice $(n=4)$ and plasma PTX concentrations were measured at various timepoints over $72 \mathrm{~h}$. The PTX concentration of the conjugates (Fig 4A) along with PTX (A) and PTX-Lev (B) formed in circulation after administration were tracked by LC-MS/MS. The data were fit to a two-compartment model to yield the parameters shown in Table S3C. The data show that mice treated with ZIPP-PTX micelles have a higher plasma concentration of PTX and PTX-Lev than mice treated with ELP-PTX. C. Biodistribution of Cy 5.5 labeled ELPPTX and ZIPP-PTX micelles after $72 \mathrm{~h}$ of injection. Even in this small study $(\mathrm{n}=2)$, it is apparent that ZIPP-PTX have higher tumor accumulation with lower uptake in the liver, likely owing to its zwitterionic nature that confers stealth behavior to the nanoparticles D. Visualization of Cy5.5 labeled ZIPP-PTX and ELP-PTX and their accumulation in tumor tissue. (i) Immunofluorescence images of tumor tissue from mice at $72 \mathrm{~h}$ and $168 \mathrm{~h}$ post injection. Tissue samples were stained with Hoechst (blue) for cell nuclei and red denotes the nanoparticles. Fluorescence quantification of tumor accumulation at $72 \mathrm{~h}$ (ii) and $168 \mathrm{~h}$ (iii). Scale bars denote $200 \mu \mathrm{m}$. ( ${ }^{*} \mathrm{P}<0.05$ and ${ }^{* * *} \mathrm{P}<0.001$, Student's t-test). 

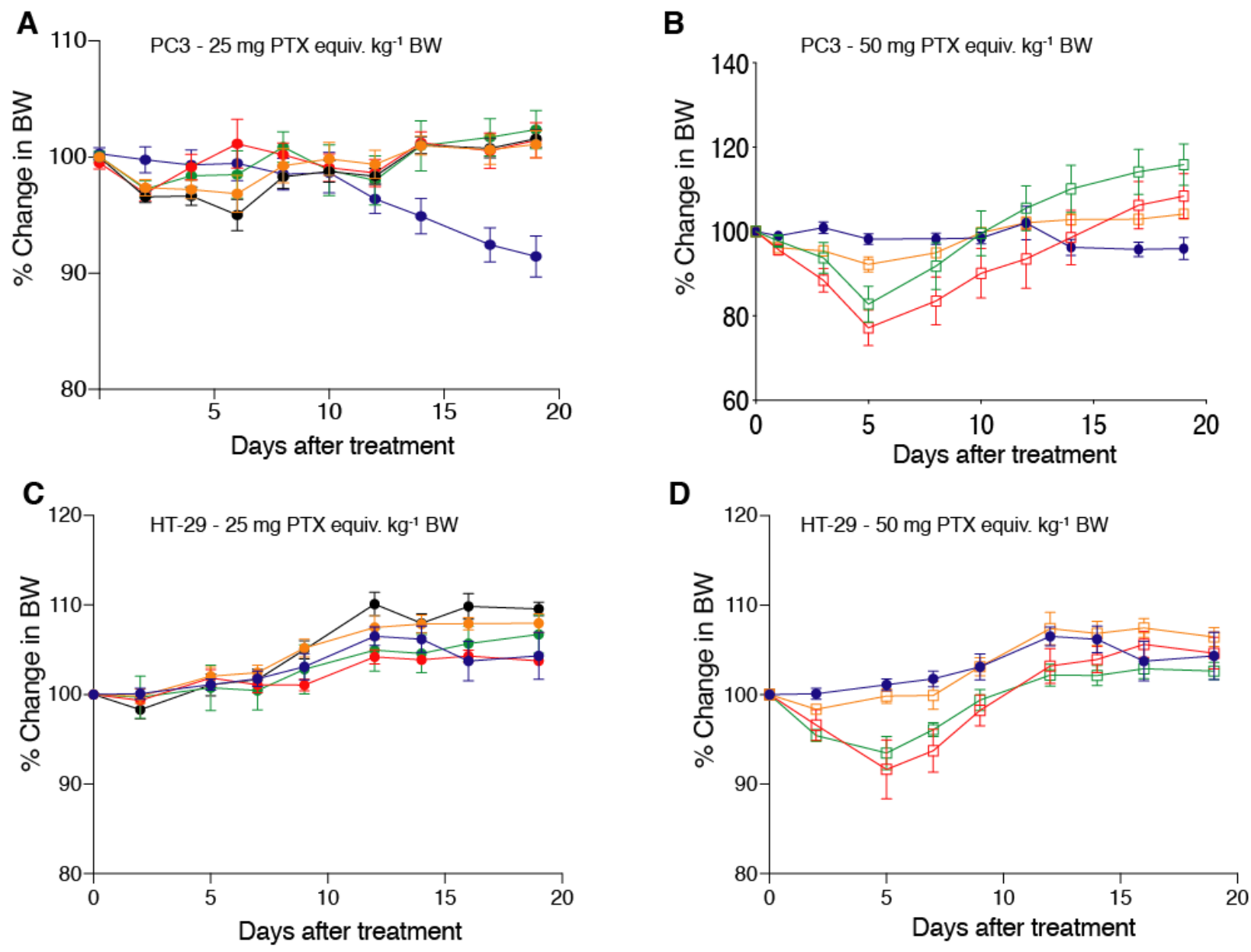

$$
\begin{array}{lll}
- & - \text { nAb } 25 \mathrm{mg} \text { PTX equiv. } \mathrm{kg}^{-1} \mathrm{BW} & - \text { Untreated } \\
- \text { PTX } 25 \mathrm{mg} \text { PTX equiv. } \mathrm{kg}^{-1} \mathrm{BW} & \bullet & \text { nAb } 50 \mathrm{mg} \text { PTX equiv. } \mathrm{kg}^{-1} \mathrm{BW} \\
- \text { ELP-PTX } 25 \mathrm{mg} \text { PTX equiv. kg-1 BW } & \bullet & \text { ELP-PTX } 50 \mathrm{mg} \text { PTX equiv. } \mathrm{kg}^{-1} \mathrm{BW} \\
- \text { ZIPP-PTX } 25 \mathrm{mg} \text { PTX equiv. } \mathrm{kg}^{-1} \mathrm{BW} & \square & \text { ZIPP-PTX } 50 \mathrm{mg} \text { PTX equiv. } \mathrm{kg}^{-1} \mathrm{BW}
\end{array}
$$

Fig. S6. Change in body weight of tumor bearing mice after treatment.

A-B. Change in body weight of PC3 tumor bearing mice treated with ZIPP-PTX, ELP-PTX, Abraxane (nAb), and free PTX at 25 mg PTX equiv. $\mathrm{kg}^{-1}$ BW (A) as discussed in Figure 5A, and (B) $50 \mathrm{mg}$ PTX equiv. $\mathrm{kg}^{-1} \mathrm{BW}^{2}$ as discussed in Figure $5 \mathrm{~B}$. C-D. Change in body weight of HT-29 tumor bearing mice treated with ZIPP-PTX, ELP-PTX, Abraxane

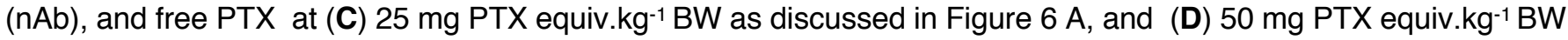
as discussed in Figure 6 B. 
A

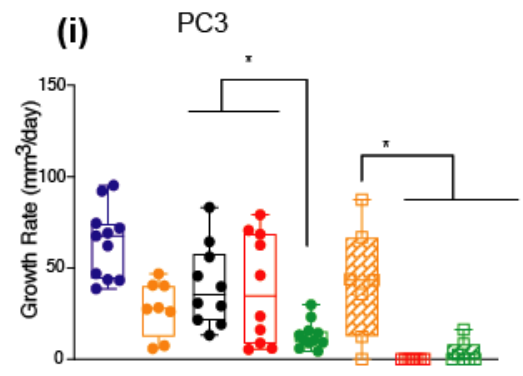

$$
\begin{aligned}
& \square \text { Untreated } \\
& \square \text { nAb } 25 \text { mg PTX equiv.kg-1 BW } \\
& \square \text { PTX } 25 \text { mg equiv.kg } \text { BW }^{-1} \\
& \square \text { ZIPP-PTX } 25 \text { mg PTX equiv.kg }{ }^{-1} \text { BW } \\
& \square \text { ELP-PTX } 25 \text { mg PTX equiv.kg }{ }^{-1} \text { BW }
\end{aligned}
$$

B

(i)
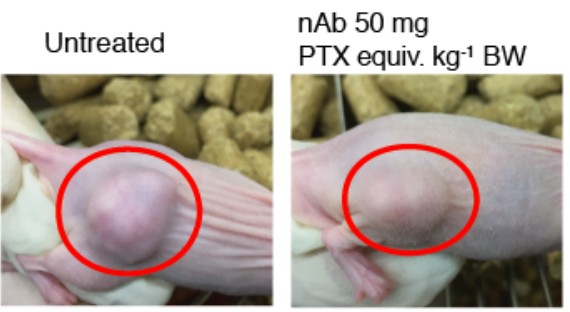

$$
\begin{aligned}
& \text { nAb } 50 \mathrm{mg} \text { PTX equiv.kg }{ }^{-1} \mathrm{BW}^{-1} \\
& \text { ZIPP-PTX } 50 \mathrm{mg} \text { PTX equiv.kg }{ }^{-1} \mathrm{BW} \\
& \text { ELP-PTX } 50 \mathrm{mg} \mathrm{PTX} \mathrm{equiv.kg}^{-1} \mathrm{BW}
\end{aligned}
$$

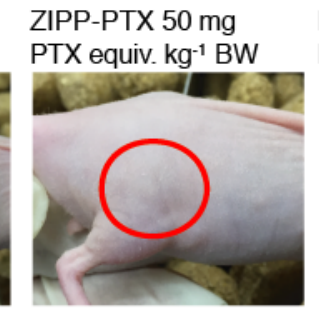

ELP-PTX $50 \mathrm{mg}$ PTX equiv. $\mathrm{kg}^{-1} \mathrm{BW}$

(ii) Untreated
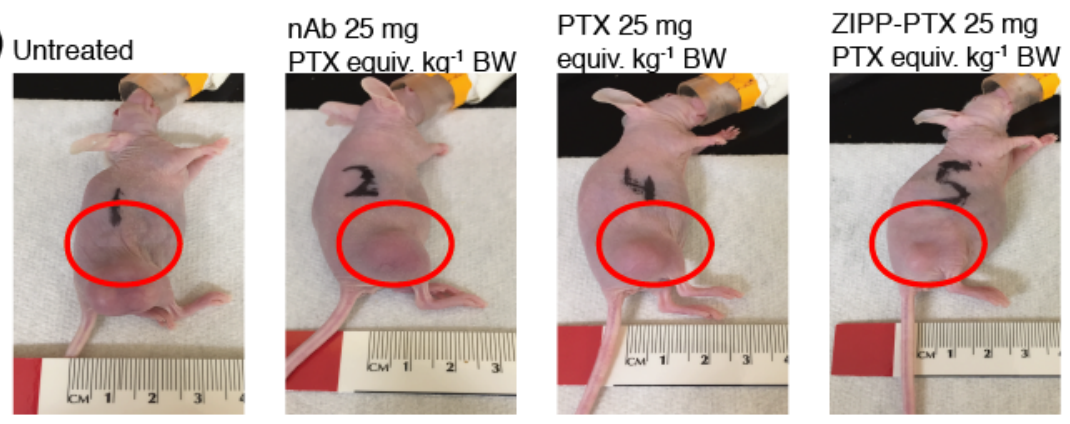

ELP-PTX $25 \mathrm{mg}$

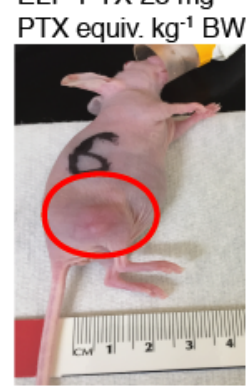

(iii)

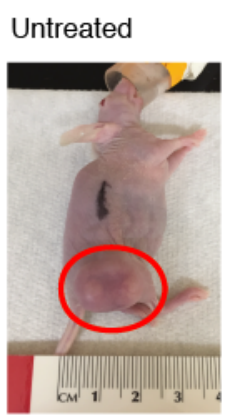

nAb 50 mg

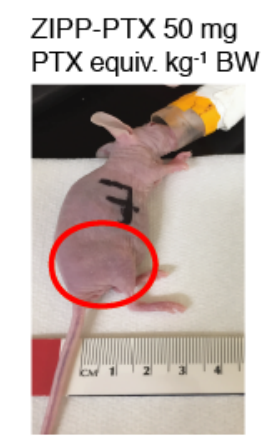

ELP-PTX $50 \mathrm{mg}$ PTX equiv. $\mathrm{kg}^{-1} \mathrm{BW}$

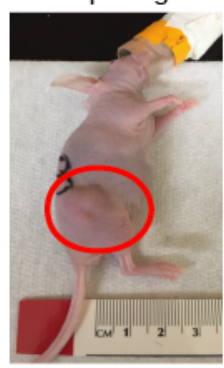

PTX equiv. $\mathrm{kg}^{-1} \mathrm{BW}$

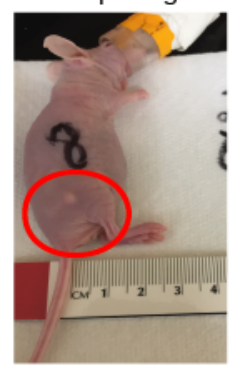

Fig. S7. Summary of tumor efficacy studies at 25 mg PTX equiv.kg-1 BW and 50 mg PTX equiv. $\mathrm{kg}^{-1}$ BW.

A. Box and whisker plot of tumor growth rate. (i) PC3 and (ii) HT-29 tumor bearing mice were treated with various formulations and their growth rate post-drug administration was compared. Treatment with ZIPP-PTX resulted in slower tumor growth compared to all other treatment groups. ( ${ }^{*} \mathrm{P}<0.05$, One-way ANOVA, Tukey's post-hoc test). B. (i) Photographs of PC3 tumor-bearing mice treated with a single bolus injection of 50 mg PTX equiv. $\mathrm{kg}^{-1} \mathrm{BW}$ of either Abraxane (nAb), ELP-PTX or ZIPP-PTX. Mice were treated on day 0 . Images were taken on day 17 for untreated mice and day 25 for Abraxane (nAb), ZIPP-PTX and ELP-PTX treated mice. Photographs show that both ZIPP-PTX and ELP-PTX were able to completely eradicate established tumors with a single dose. (ii-iii) Photographs of HT29 tumor-bearing mice treated with a single bolus injection of (i) $25 \mathrm{mg}$ PTX equiv. $\mathrm{kg}^{-1}$ BW of either free PTX,

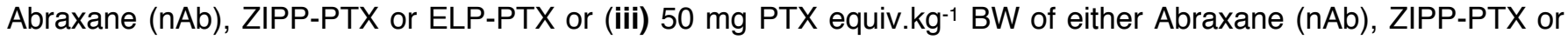
ELP-PTX. Mice were treated on day 0. Photographs were taken on day 14 post-treatment. Photos show that mice treated with ZIPP-PTX have slower tumor growth compared to other treatment groups. 

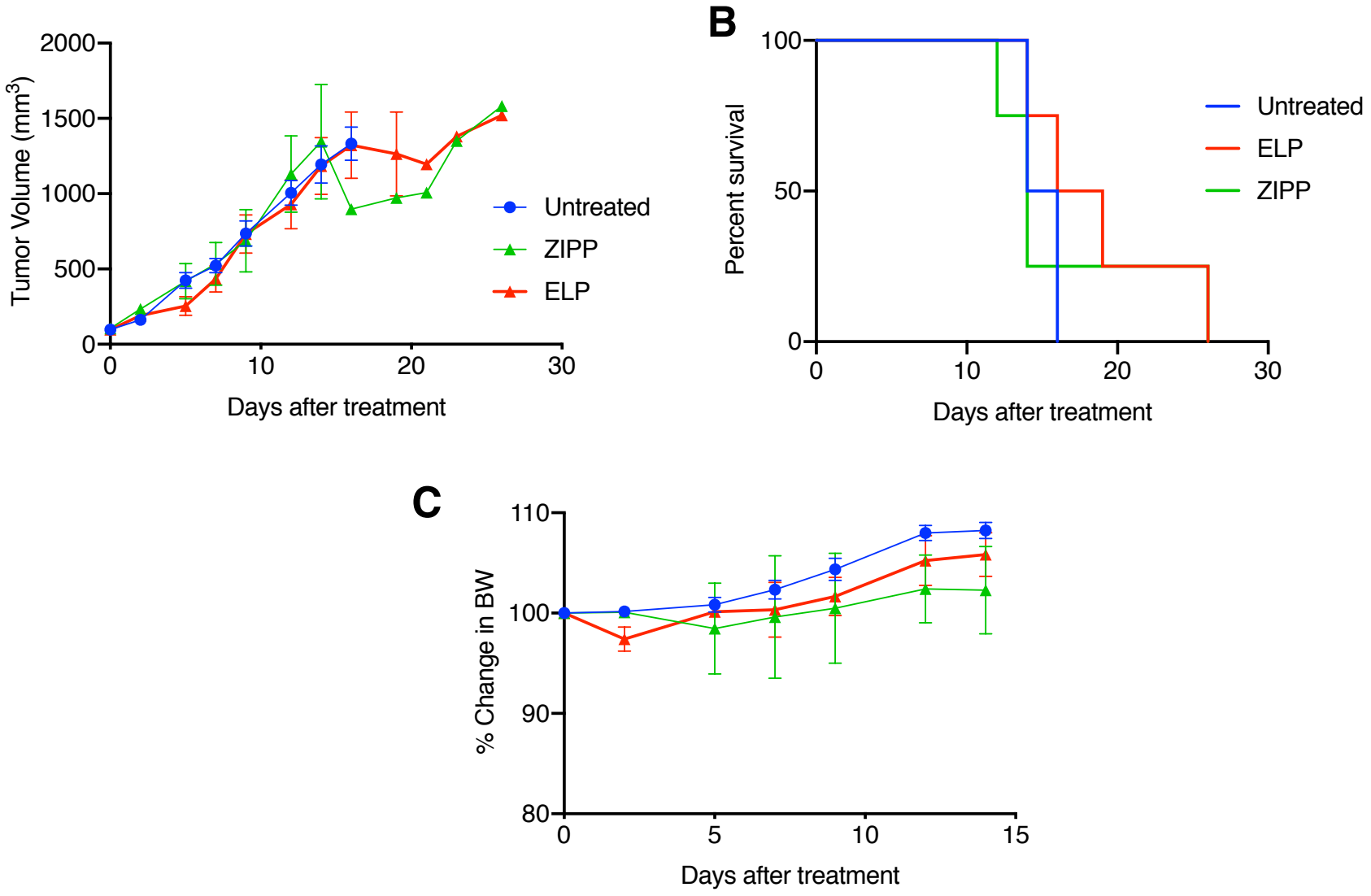

Fig. S8. Tumor response data for ZIPP and ELP without paclitaxel in subcutaneous HT-29 colon cancer xenograft model.

A. Tumor growth data; mice bearing HT-29 tumor were treated with ZIPP and ELP unimers at a protein concentration equivalent to 50 mg PTX equiv. $\mathrm{kg}^{-1}$ BW on day 0 . Results indicate that both ZIPP and ELPs have no effect on tumor growth inhibition. B. Kaplan-Meier survival analysis indicates that polypeptides without any drug have identical median survival as the untreated group. C. Change in BW up to 15 days after treatment. 

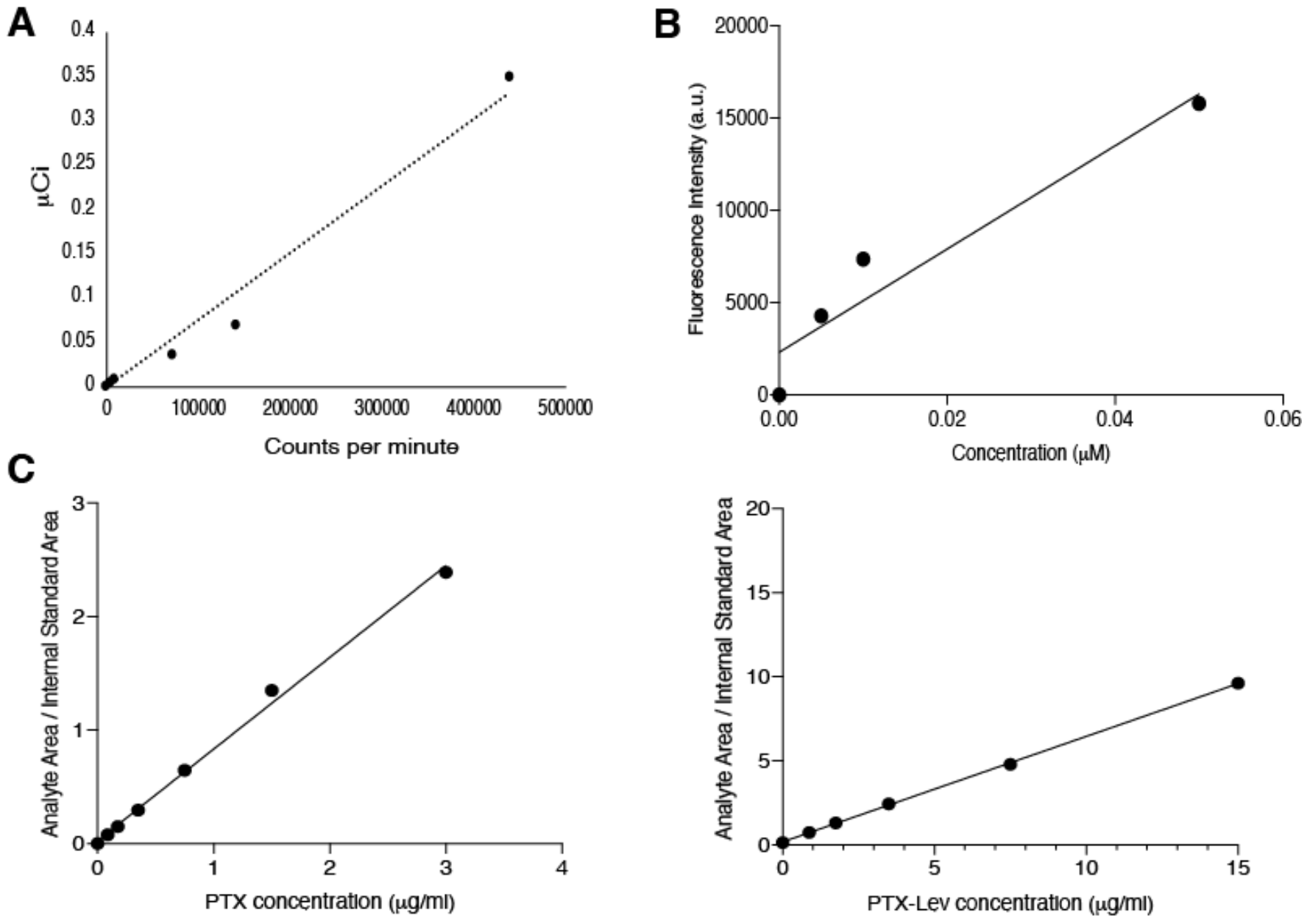

D
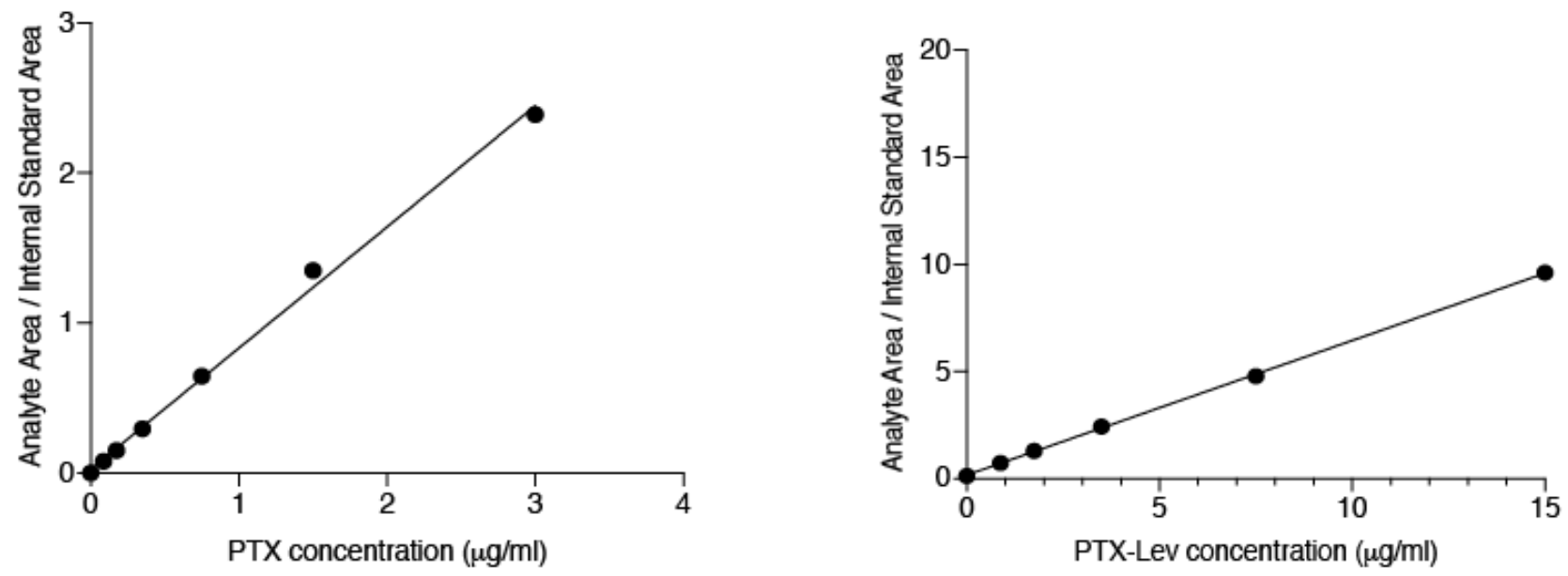

Fig. S9. Standard curves used across various studies.

A. Radioactivity standard curve for unimer PK study. B. Fluorescence standard curve for ELP-Cy5 and ZIPP-Cy5 nanoparticle PK study. C. Standard curve generated from LC-MS/MS data for quantification of PTX and PTX-Lev for in vitro drug release study. D. Standard curve generated from LC-MS/MS data for quantification of PTX and PTX-Lev in plasma for PK study of ELP-PTX and ZIPP-PTX micelles 


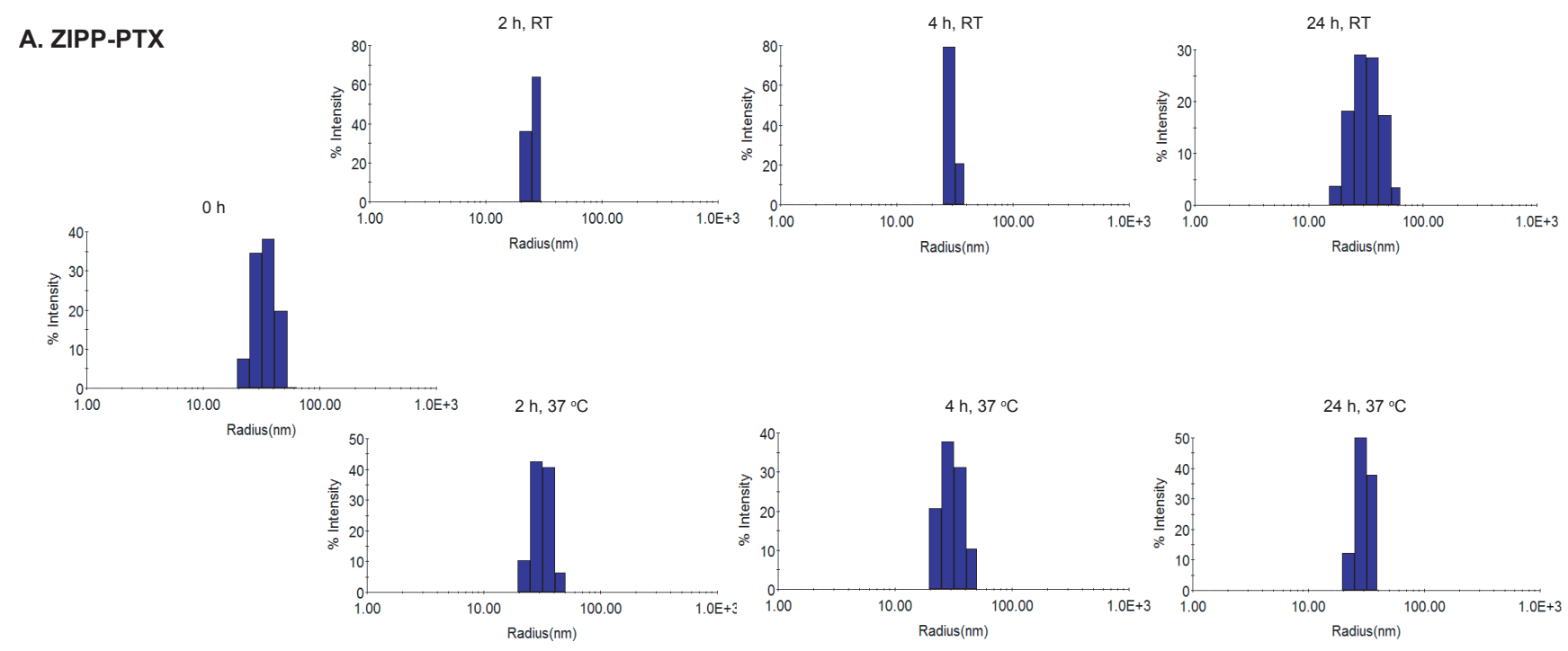

B. ELP-PTX
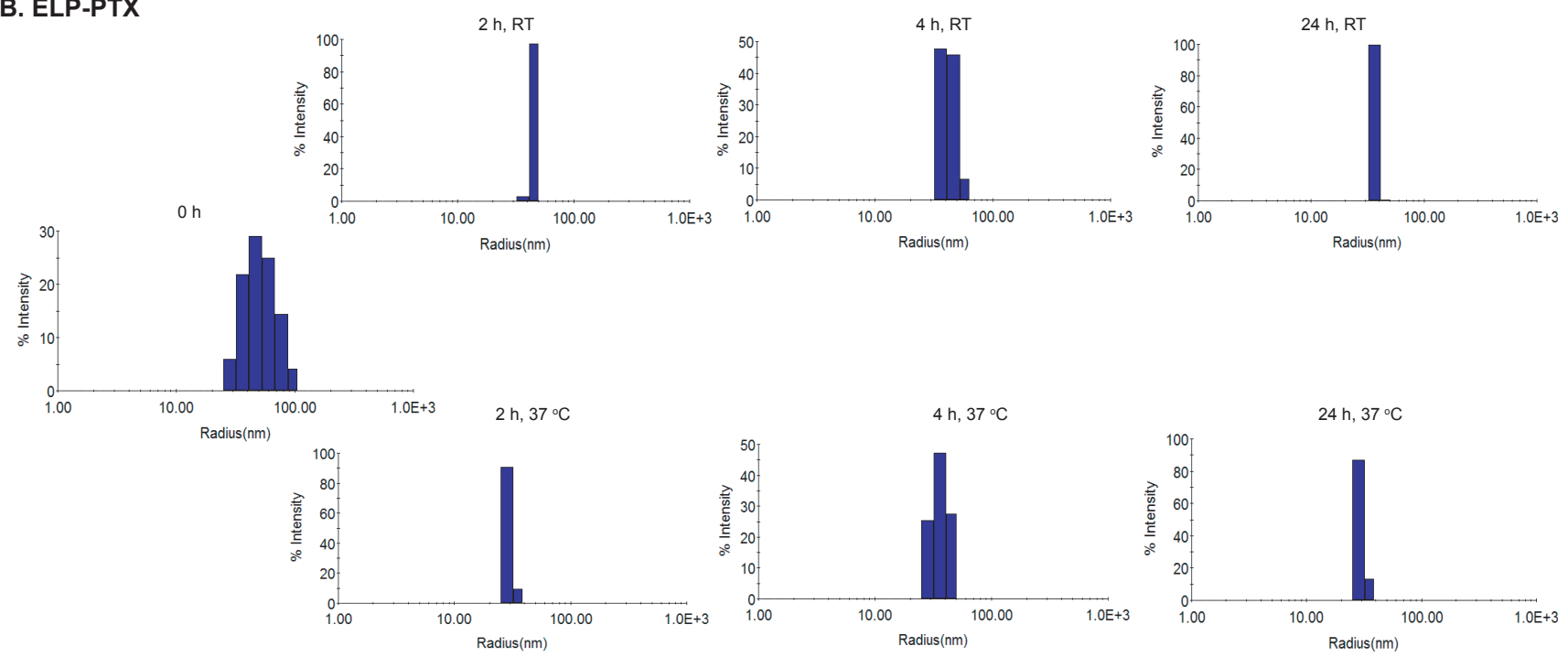

Fig. S10: Stability Data for ZIPP-PTX and ELP-PTX.

Stability of ZIPP-PTX (A) and ELP-PTX (B) micelles at room-temperature (RT) and $37^{\circ} \mathrm{C}$. 

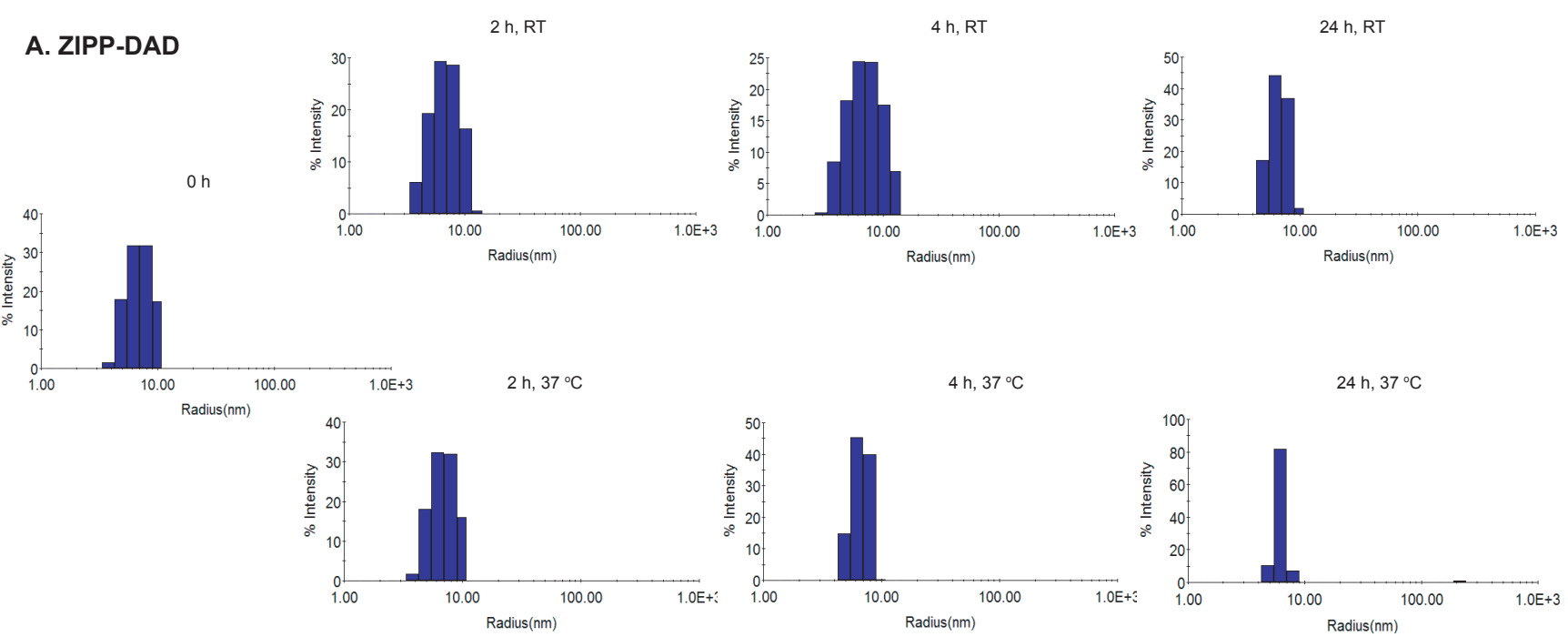

B. ELP-DAD
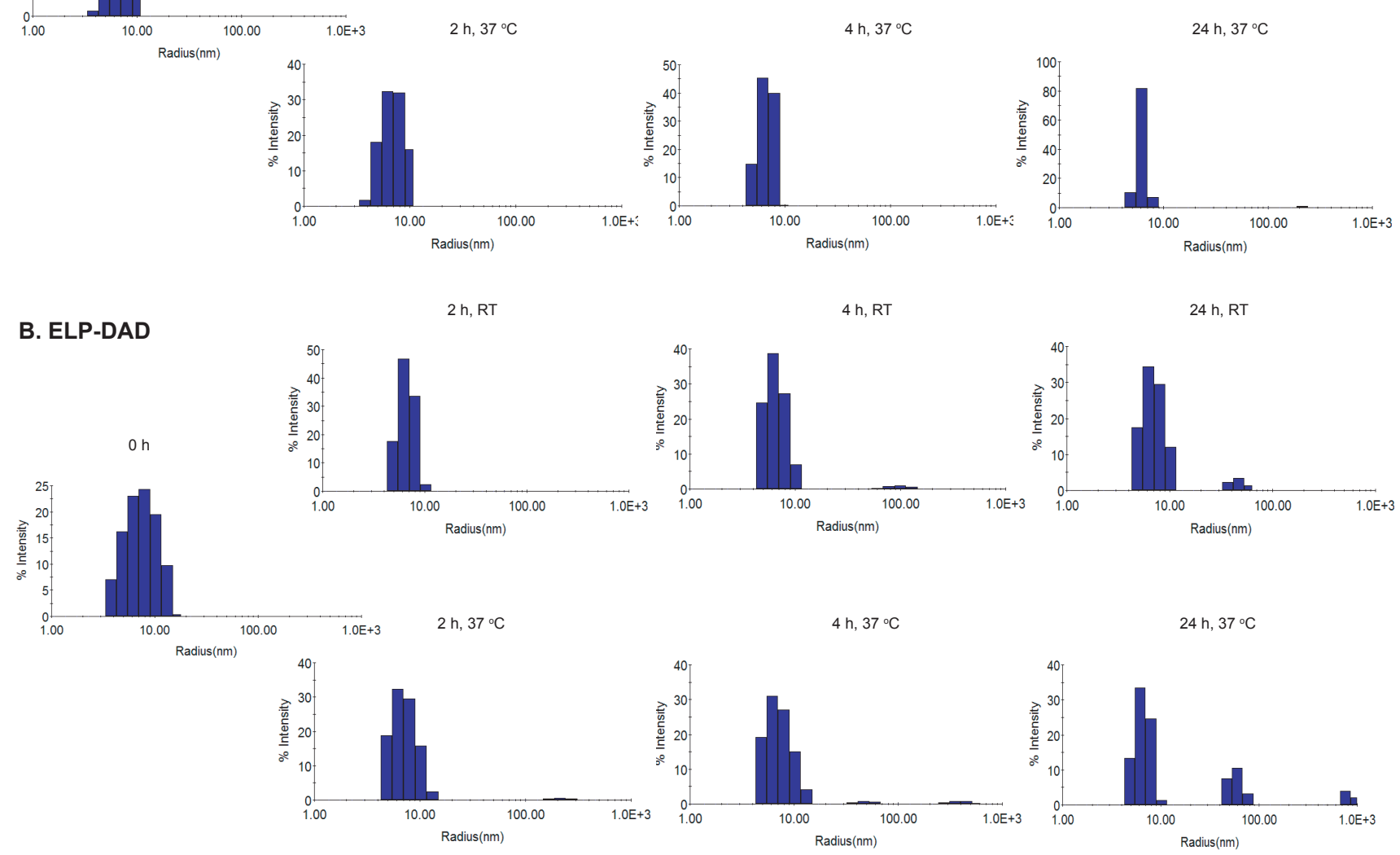

Radius(nm)

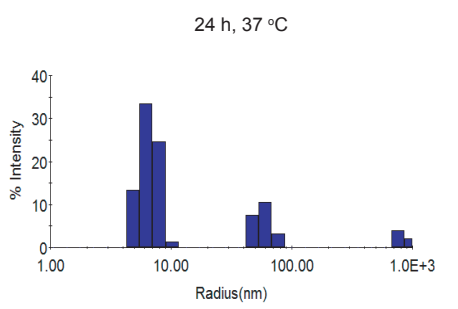

Fig. S11: Stability Data for ZIPP-DAD and ELP-DAD.

Stability of ZIPP-DAD (A) and ELP-DAD (B) micelles at room-temperature (RT) and $37^{\circ} \mathrm{C}$. 
Table S1. Amino acid sequence of ELP and ZIPP used for paclitaxel delivery.

\begin{tabular}{|c|c|c|}
\hline $\begin{array}{l}\text { Sequence } \\
\text { name }\end{array}$ & Full sequence & $\begin{array}{l}\text { Molecular } \\
\text { Weight (Da) }\end{array}$ \\
\hline $\begin{array}{l}\text { ELP }{ }_{160} \text {-DAD- } \\
\text { WP }\end{array}$ & $\begin{array}{l}\text { SKGPG } \text { AG VPGGG VPGAG VPGGG VPGAG VPGGG VPGAG VPGGG } \\
\text { VPGAG VPGGG VPGAG VPGGG VPGAG VPGGG VPGAG VPGGG } \\
\text { VPGAG VPGGG VPGAG VPGGG VPGAG VPGGG VPGAG VPGGG } \\
\text { VPGAG VPGGG VPGAG VPGGG VPGAG VPGGG VPGAG VPGGG } \\
\text { VPGAG VPGGG VPGAG VPGGG VPGAG VPGGG VPGAG VPGGG } \\
\text { VPGAG VPGGG VPGAG VPGGG VPGAG VPGGG VPGAG VPGGG } \\
\text { VPGAG VPGGG VPGAG VPGGG VPGAG VPGGG VPGAG VPGGG } \\
\text { VPGAG VPGGG VPGAG VPGGG VPGAG VPGGG VPGAG VPGGG } \\
\text { VPGAG VPGGG VPGAG VPGGG VPGAG VPGGG VPGAG VPGGG } \\
\text { VPGAG VPGGG VPGAG VPGGG VPGAG VPGGG VPGAG VPGGG } \\
\text { VPGAG VPGGG VPGAG VPGGG VPGAG VPGGG VPGAG VPGGG } \\
\text { VPGAG VPGGG VPGAG VPGGG VPGAG VPGGG VPGAG VPGGG } \\
\text { VPGAG VPGGG VPGAG VPGGG VPGAG VPGGG VPGAG VPGGG } \\
\text { VPGAG VPGGG VPGAG VPGGG VPGAG VPGGG VPGAG VPGGG } \\
\text { VPGAG VPGGG VPGAG VPGGG VPGAG VPGGG VPGAG VPGGG } \\
\text { VPGAG VPGGG VPGAG VPGGG VPGAG VPGGG VPGAG VPGGG } \\
\text { VPGAG VPGGG VPGAG VPGGG VPGAG VPGGG VPGAG VPGGG } \\
\text { VPGAG VPGGG VPGAG VPGGG VPGAG VPGGG VPGAG VPGGG } \\
\text { VPGAG VPGGG VPGAG VPGGG VPGAG VPGGG VPGAG VPGGG } \\
\text { VPGAG VPGGG VPGAG VPGGG VPGAG VPGGG VPGAG VPGGG } \\
\text { VPG CG VPGVG VPGCG VPGVG VPGCG VPG VG VPGCG VPGVG } \\
\text { VPGCG VPGVG VPGCG VPGVG VPGCG VPGVG VPGCG VPGVG } \\
\text { VPG WP }\end{array}$ & 67218 \\
\hline $\begin{array}{l}\text { ZIPP }_{120-D A D-} \\
\text { WP }\end{array}$ & $\begin{array}{l}\text { SKGPG VPKEG VPKEG VPKEG VPKEG VPKEG VPKEG VPKEG } \\
\text { VPKEG VPKEG VPKEG VPKEG VPKEG VPKEG VPKEG VPKEG } \\
\text { VPKEG VPKEG VPKEG VPKEG VPKEG VPKEG VPKEG VPKEG } \\
\text { VPKEG VPKEG VPKEG VPKEG VPKEG VPKEG VPKEG VPKEG } \\
\text { VPKEG VPKEG VPKEG VPKEG VPKEG VPKEG VPKEG VPKEG } \\
\text { VPKEG VPKEG VPKEG VPKEG VPKEG VPKEG VPKEG VPKEG } \\
\text { VPKEG VPKEG VPKEG VPKEG VPKEG VPKEG VPKEG VPKEG } \\
\text { VPKEG VPKEG VPKEG VPKEG VPKEG VPKEG VPKEG VPKEG } \\
\text { VPKEG VPKEG VPKEG VPKEG VPKEG VPKEG VPKEG VPKEG } \\
\text { VPKEG VPKEG VPKEG VPKEG VPKEG VPKEG VPKEG VPKEG } \\
\text { VPKEG VPKEG VPKEG VPKEG VPKEG VPKEG VPKEG VPKEG } \\
\text { VPKEG VPKEG VPKEG VPKEG VPKEG VPKEG VPKEG VPKEG } \\
\text { VPKEG VPKEG VPKEG VPKEG VPKEG VPKEG VPKEG VPKEG } \\
\text { VPKEG VPKEG VPKEG VPKEG VPKEG VPKEG VPKEG VPKEG } \\
\text { VPKEG VPKEG VPKEG VPKEG VPKEG VPKEG VPKEG VPKEG } \\
\text { VPKEG CG VPGVG VPGCG VPGVG VPGCG VPGVG VPGCG VPGVG } \\
\text { VPGCG VPGVG VPGCG VPGVG VPGCG VPGVG VPGCG VPGVG } \\
\text { VPG WP }\end{array}$ & 68582 \\
\hline $\begin{array}{l}\text { ELP }_{160}-\mathrm{DAD}-\mathrm{Y} \\
\text { (Sequence } \\
\text { used for unimer } \\
\text { PK study) }\end{array}$ & $\begin{array}{l}\text { SKGPG AG VPGGG VPGAG VPGGG VPGAG VPGGG VPGAG VPGGG } \\
\text { VPGAG VPGGG VPGAG VPGGG VPGAG VPGGG VPGAG VPGGG } \\
\text { VPGAG VPGGG VPGAG VPGGG VPGAG VPGGG VPGAG VPGGG } \\
\text { VPGAG VPGGG VPGAG VPGGG VPGAG VPGGG VPGAG VPGGG } \\
\text { VPGAG VPGGG VPGAG VPGGG VPGAG VPGGG VPGAG VPGGG } \\
\text { VPGAG VPGGG VPGAG VPGGG VPGAG VPGGG VPGAG VPGGG } \\
\text { VPGAG VPGGG VPGAG VPGGG VPGAG VPGGG VPGAG VPGGG } \\
\text { VPGAG VPGGG VPGAG VPGGG VPGAG VPGGG VPGAG VPGGG } \\
\text { VPGAG VPGGG VPGAG VPGGG VPGAG VPGGG VPGAG VPGGG }\end{array}$ & 67098 \\
\hline
\end{tabular}




\begin{tabular}{|c|c|c|}
\hline & $\begin{array}{l}\text { VPGAG VPGGG VPGAG VPGGG VPGAG VPGGG VPGAG VPGGG } \\
\text { VPGAG VPGGG VPGAG VPGGG VPGAG VPGGG VPGAG VPGGG } \\
\text { VPGAG VPGGG VPGAG VPGGG VPGAG VPGGG VPGAG VPGGG } \\
\text { VPGAG VPGGG VPGAG VPGGG VPGAG VPGGG VPGAG VPGGG } \\
\text { VPGAG VPGGG VPGAG VPGGG VPGAG VPGGG VPGAG VPGGG } \\
\text { VPGAG VPGGG VPGAG VPGGG VPGAG VPGGG VPGAG VPGGG } \\
\text { VPGAG VPGGG VPGAG VPGGG VPGAG VPGGG VPGAG VPGGG } \\
\text { VPGAG VPGGG VPGAG VPGGG VPGAG VPGGG VPGAG VPGGG } \\
\text { VPGAG VPGGG VPGAG VPGGG VPGAG VPGGG VPGAG VPGGG } \\
\text { VPGAG VPGGG VPGAG VPGGG VPGAG VPGGG VPGAG VPGGG } \\
\text { VPGAG VPGGG VPGAG VPGGG VPGAG VPGGG VPGAG VPGGG } \\
\text { VPG CG VPGVG VPGCG VPGVG VPGCG VPGVG VPGCG VPGVG } \\
\text { VPGCG VPGVG VPGCG VPGVG VPGCG VPGVG VPGCG VPGVG } \\
\text { VPG Y }\end{array}$ & \\
\hline $\begin{array}{l}\text { ZIPP }_{120-D A D-Y} \\
\text { (Sequence } \\
\text { used for unimer } \\
\text { PK study) }\end{array}$ & $\begin{array}{l}\text { SKGPG VPKEG VPKEG VPKEG VPKEG VPKEG VPKEG VPKEG } \\
\text { VPKEG VPKEG VPKEG VPKEG VPKEG VPKEG VPKEG VPKEG } \\
\text { VPKEG VPKEG VPKEG VPKEG VPKEG VPKEG VPKEG VPKEG } \\
\text { VPKEG VPKEG VPKEG VPKEG VPKEG VPKEG VPKEG VPKEG } \\
\text { VPKEG VPKEG VPKEG VPKEG VPKEG VPKEG VPKEG VPKEG } \\
\text { VPKEG VPKEG VPKEG VPKEG VPKEG VPKEG VPKEG VPKEG } \\
\text { VPKEG VPKEG VPKEG VPKEG VPKEG VPKEG VPKEG VPKEG } \\
\text { VPKEG VPKEG VPKEG VPKEG VPKEG VPKEG VPKEG VPKEG } \\
\text { VPKEG VPKEG VPKEG VPKEG VPKEG VPKEG VPKEG VPKEG } \\
\text { VPKEG VPKEG VPKEG VPKEG VPKEG VPKEG VPKEG VPKEG } \\
\text { VPKEG VPKEG VPKEG VPKEG VPKEG VPKEG VPKEG VPKEG } \\
\text { VPKEG VPKEG VPKEG VPKEG VPKEG VPKEG VPKEG VPKEG } \\
\text { VPKEG VPKEG VPKEG VPKEG VPKEG VPKEG VPKEG VPKEG } \\
\text { VPKEG VPKEG VPKEG VPKEG VPKEG VPKEG VPKEG VPKEG } \\
\text { VPKEG VPKEG VPKEG VPKEG VPKEG VPKEG VPKEG VPKEG } \\
\text { VPKEG CG VPGVG VPGCG VPGVG VPGCG VPGVG VPGCG VPGVG } \\
\text { VPGCG VPGVG VPGCG VPGVG VPGCG VPGVG VPGCG VPGVG } \\
\text { VPG Y }\end{array}$ & 68462 \\
\hline
\end{tabular}

Table S2. Hydrodynamic radius of ZIPP and ELP nanoparticles formed after Cy5 conjugation.

\begin{tabular}{cc}
\hline & $\mathrm{R}_{\mathrm{h}}(\mathrm{nm})$ \\
\hline ZIPP-Cy5 & $49.9 \pm 2.2$ \\
ELP-Cy5 & $35.6 \pm 1.0$ \\
\hline
\end{tabular}


Table S3. Pharmacokinetic parameters from various PK studies

A. Pharmacokinetic parameters of ZIPP-DAD and ELP-DAD unimers.

\begin{tabular}{lll}
\hline & ZIPP-DAD & ELP-DAD \\
\hline $\mathrm{t}_{1 / 2}(\mathrm{~h})$ & $15.6 \pm 0.40$ & $6.4 \pm 0.10$ \\
\hline $\mathrm{V}_{\mathrm{d}}(\mathrm{ml})$ & $2.0 \pm 0.02$ & $1.7 \pm 0.10$ \\
\hline $\mathrm{Cl}\left(\mathrm{ml} \mathrm{hr}^{-1}\right)$ & $0.15 \pm 0.01$ & $0.23 \pm 0.00$ \\
\hline $\mathrm{AUC}(\mathrm{nM} \mathrm{hr})$ & $384170 \pm 12474$ & $256400 \pm 2227$ \\
\hline
\end{tabular}

B. Pharmacokinetic parameters of ZIPP-Cy5 and ELP-Cy5 nanoparticles.

\begin{tabular}{lll}
\hline & ZIPP- Cy 5 & ELP-Cy 5 \\
\hline $\mathrm{t}_{1 / 2}(\mathrm{~h})$ & $18.2 \pm 2.9$ & $12.2 \pm 0.6$ \\
\hline $\mathrm{Vd}(\mathrm{ml})$ & $5.2 \pm 0.2$ & $10.8 \pm 0.8$ \\
\hline $\mathrm{Cl}\left(\mathrm{ml} \mathrm{hr}^{-1}\right)$ & $1.4 \pm 0.1$ & $3.5 \pm 0.3$ \\
\hline $\mathrm{AUC}(\mathrm{nM} \mathrm{hr})$ & $1866 \pm 129$ & $573 \pm 43$ \\
\hline
\end{tabular}

C. Pharmacokinetic parameters of ZIPP-PTX and ELP-PTX and nanoparticles and free PTX.

\begin{tabular}{lc|ccc|ccc}
\hline & Free PTX & \multicolumn{3}{c|}{ ZIPP-PTX } & \multicolumn{3}{c}{ ELP-PTX } \\
\hline & PTX & PTX & PTX-Lev & ZIPP-PTX & PTX & PTX-Lev & ZIPP-PTX \\
\hline $\begin{array}{l}\mathrm{t}_{1 / 2} \\
(\mathrm{~h})\end{array}$ & $1.1 \pm 0.2$ & $15.5 \pm 0.3$ & $12.9 \pm 0.7$ & $18.7 \pm 1.2$ & $22.5 \pm 2.2$ & $13.8 \pm 0.6$ & $11.8 \pm 0.2$ \\
\hline $\begin{array}{l}\mathrm{V}_{\mathrm{d}} \\
\left(\mathrm{L} \mathrm{kg}^{-1}\right)\end{array}$ & $1.9 \pm 0.3$ & $19.4 \pm 2.9$ & $2.2 \pm 0.2$ & $0.2 \pm 0.01$ & $61.0 \pm 8.7$ & $4.4 \pm 0.5$ & $0.19 \pm 0.02$ \\
\hline $\begin{array}{l}\mathrm{Cl} \\
\left(\mathrm{L} \mathrm{hr-}{ }^{-1} \mathrm{~kg}^{-1}\right)\end{array}$ & $1.2 \pm 0.2$ & $2.2 \pm 0.2$ & $0.4 \pm 0.01$ & $0.02 \pm 0.0$ & $5.1 \pm 0.2$ & $0.6 \pm 0.1$ & $0.01 \pm 0.0$ \\
\hline $\begin{array}{l}\mathrm{AUC} \\
(\mathrm{nM} \mathrm{hr})\end{array}$ & $\begin{array}{c}22,888 \\
\pm\end{array}$ & $\begin{array}{c}10,864 \\
\pm\end{array}$ & $\begin{array}{c}63,408 \\
\pm\end{array}$ & $\begin{array}{c}1,578,258 \\
\pm\end{array}$ & $\begin{array}{c}4,564 \\
\pm\end{array}$ & $\begin{array}{c}39,741 \\
\pm\end{array}$ & $\begin{array}{c}1,854,032 \\
\pm\end{array}$ \\
\hline & & 727 & 1,647 & 228,154 & 201 & 4,010 & 219,523 \\
\hline
\end{tabular}


Table S4. Summary of tumor response for PC3 and HT-29 xenograft models.

A. PC3 tumor model

\begin{tabular}{lllc}
\hline & $\begin{array}{l}\text { Growth rate } \\
\left(\mathrm{mm}^{3} / \text { day) }\right.\end{array}$ & $\begin{array}{l}\text { T/C } \\
\text { ratio }^{\mathrm{a}}\end{array}$ & $\begin{array}{c}\text { Median Survival } \\
\text { (days) }\end{array}$ \\
\hline Untreated & $64.13 \pm 5.84$ & & 20 \\
nAb 25 mg PTX equiv. $\mathrm{kg}^{-1} \mathrm{BW}$ & $27.88 \pm 5.29$ & 0.15 & 36 \\
PTX 25 mg equiv.kg-1 BW & $40.34 \pm 7.02$ & 0.27 & 34 \\
ELP-PTX 25 mg PTX equiv.kg-1 BW & $38.72 \pm 9.40$ & 0.30 & 34 \\
ZIPP-PTX 25 mg PTX equiv.kg-1 BW & $13.30 \pm 2.26$ & 0.10 & 48 \\
Untreated & $68.88 \pm 9.56$ & & 19 \\
nAb 50 mg PTX equiv.kg-1 BW & $41.43 \pm 11.31$ & 0.03 & 41 \\
ELP-PTX 50 mg PTX equiv.kg-1 BW & $0.00 \pm 0.00$ & 0.00 & -- \\
ZIPP-PTX 50 mg PTX equiv. $\mathrm{kg}^{-1} \mathrm{BW}$ & $3.94 \pm 2.38$ & 0.00 & -- \\
\hline
\end{tabular}

aT/C ratio is defined as the mean tumor volume of treated animals $(T)$ divided by mean tumor volume of control animals (C). T/C ratio was calculated at the last day where all the groups had treatment values (Day 17). T/C ratio less than 0.15 is considered high activity response, $0.15-0.45$ is considered intermediate (Int) activity and greater than 0.45 is considered low activity response.

bMedian survival calculated from Kaplan-Meier Estimate of median days to pre-determined end-point of $1500 \mathrm{~mm}^{3}$ tumor volume.

B. HT-29 tumor model

\begin{tabular}{lllc}
\hline & $\begin{array}{l}\text { Growth rate } \\
\left(\mathrm{mm}^{3} / \text { day) }\right.\end{array}$ & $\begin{array}{l}\text { T/C } \\
\text { ratio }^{\mathrm{a}}\end{array}$ & $\begin{array}{c}\text { Median Survival } \\
\text { (days) }\end{array}$ \\
\hline Untreated & $90.44 \pm 8.30$ & & 18 \\
nAb 25 mg PTX equiv.kg-1 BW & $76.38 \pm 10.03$ & 0.55 & 23 \\
PTX 25 mg equiv.kg-1 BW & $80.98 \pm 9.43$ & 0.46 & 23 \\
ELP-PTX 25 mg PTX equiv.kg-1 BW & $47.53 \pm 6.14$ & 0.18 & 30 \\
ZIPP-PTX 25 mg PTX equiv.kg-1 BW & $37.64 \pm 6.83$ & 0.11 & 35 \\
& & & \\
nAb 50 mg PTX equiv.kg-1 BW & $72.60 \pm 4.87$ & 0.24 & 28 \\
ELP-PTX 50 mg PTX equiv.kg-1 BW & $45.74 \pm 5.31$ & 0.03 & 37 \\
ZIPP-PTX 50 mg PTX equiv.kg-1 BW & $30.10 \pm 8.31$ & 0.03 & 49 \\
\hline
\end{tabular}

aT/C ratio is defined as the mean tumor volume of treated animals $(\mathrm{T})$ divided by mean tumor volume of control animals (C). T/C ratio was calculated at the last day where all the groups had treatment values (Day 17). T/C ratio less than 0.15 is considered high activity response, $0.15-0.45$ is considered intermediate (Int) activity and greater than 0.45 is considered low activity response.

bMedian survival calculated from Kaplan-Meier Estimate of median days to pre-determined end-point of $1500 \mathrm{~mm}^{3}$ tumor volume 
Table S5. Summary of papers reporting paclitaxel nanoformulations along with in vivo studies after 2005

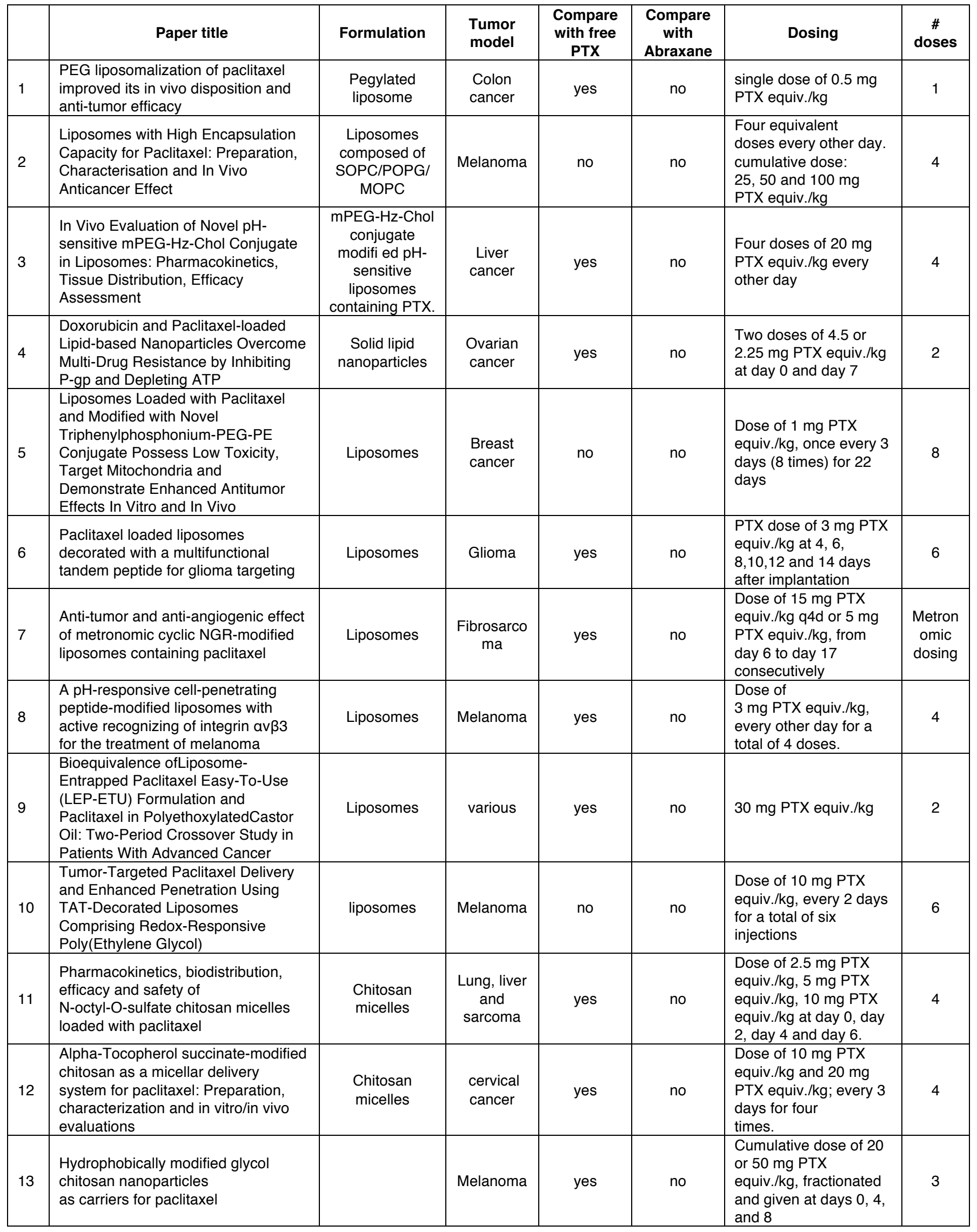




\begin{tabular}{|c|c|c|c|c|c|c|c|}
\hline 14 & $\begin{array}{l}\text { Enhanced drug-loading and } \\
\text { therapeutic efficacy of hydrotropic } \\
\text { oligomer-conjugated glycol chitosan } \\
\text { nanoparticles for tumor-targeted } \\
\text { paclitaxel delivery }\end{array}$ & $\begin{array}{l}\text { Chitosan } \\
\text { micelles }\end{array}$ & $\begin{array}{l}\text { breast } \\
\text { cancer }\end{array}$ & yes & yes & $\begin{array}{l}\text { Dose of } 20 \mathrm{mg} \text { PTX } \\
\text { equiv. } / \mathrm{kg} \text {, given } 5 \\
\text { times, every } 3 \text { days. }\end{array}$ & 5 \\
\hline 15 & $\begin{array}{l}\text { Design of a Paclitaxel Prodrug } \\
\text { Conjugate for Active Targeting of an } \\
\text { Enzyme Upregulated in Breast } \\
\text { Cancer Cells }\end{array}$ & Dendrimer & $\begin{array}{l}\text { breast } \\
\text { cancer }\end{array}$ & yes & no & $\begin{array}{l}\text { Dose of } 10 \mathrm{mg} \text { PTX } \\
\text { equiv./kg every other } \\
\text { day for three injections }\end{array}$ & 3 \\
\hline 16 & $\begin{array}{l}\text { Hyaluronic Acid-Paclitaxel: Antitumor } \\
\text { Efficacy against CD44(+) Human } \\
\text { Ovarian Carcinoma Xenografts }\end{array}$ & Hyaluronic Acid & $\begin{array}{l}\text { Ovarian } \\
\text { cancer }\end{array}$ & yes & no & $\begin{array}{l}\mathrm{HA}-\mathrm{TXL} \text { at } 100 \text { or } 200 \\
\mathrm{mg} \text { PTX equiv./kg, and } \\
\text { Taxol at } 10 \mathrm{mg} / \mathrm{kg} \text { and } \\
15 \mathrm{mg} / \mathrm{kg}\end{array}$ & 1 \\
\hline 17 & $\begin{array}{l}\text { A self-assembling nanoparticle for } \\
\text { paclitaxel delivery in ovarian cancer }\end{array}$ & Dendrimer & $\begin{array}{l}\text { Ovarian } \\
\text { cancer }\end{array}$ & yes & yes & $\begin{array}{l}\text { For s.c, dose Taxol } \\
\text { (13.4 mg PTX } \\
\text { equiv./kg); Abraxane } \\
\text { ( } 30 \mathrm{mg} \text { PTX equiv./kg) } \\
\text { and PTX-Dendrimers } \\
\text { (13.4 or } 30 \mathrm{mg} \text { PTX } \\
\text { equiv./kg), given at day } \\
0,4,8 \text { and again on } \\
\text { days } 38,42 \text { and } 46 \\
\text { For orthotopic: dose } \\
\text { Taxol (20 mg PTX } \\
\text { equiv./kg), Abraxane } \\
\text { (45 mg PTX equiv./kg), } \\
\text { or PTX-dendrimers (20 } \\
\text { or } 45 \mathrm{mg} \text { PTX } \\
\text { equiv./kg) at days } 0,4 \text {, } \\
8,12, \text { and } 16 .\end{array}$ & 5 or 6 \\
\hline 18 & $\begin{array}{l}\text { Enhanced anti-glioblastoma efficacy } \\
\text { by PTX-loaded PEGylated poly( } \varepsilon \text { - } \\
\text { caprolactone) nanoparticles: In vitro } \\
\text { and in vivo evaluation }\end{array}$ & $\begin{array}{c}\mathrm{PCL} \\
\text { nanoparticles }\end{array}$ & Glioma & yes & no & $\begin{array}{l}\text { Dose of } 10 \mathrm{mg} \text { PTX } \\
\text { equiv. } / \mathrm{kg} \text {, given on } \\
\text { days } 7,9,11,13\end{array}$ & 4 \\
\hline 19 & $\begin{array}{l}\text { Shape effects of filaments versus } \\
\text { spherical particles in flow and drug } \\
\text { delivery }\end{array}$ & $\begin{array}{c}\mathrm{PCL} \\
\text { nanoparticles }\end{array}$ & $\begin{array}{l}\text { Lung } \\
\text { cancer }\end{array}$ & yes & no & $\begin{array}{l}\text { Dose Taxol } 1 \mathrm{mg} \text { PTX } \\
\text { equiv. } / \mathrm{kg} \text { and micelles } \\
\text { (1 or } 8 \mathrm{mg} \text { PTX } \\
\text { equiv. } / \mathrm{kg} \text { ) }\end{array}$ & 1 \\
\hline 20 & $\begin{array}{l}\text { Paclitaxel-loaded PEGylated PLGA- } \\
\text { based nanoparticles: In vitro and in } \\
\text { vivo evaluation }\end{array}$ & $\begin{array}{c}\text { PLGA } \\
\text { nanoparticles }\end{array}$ & $\begin{array}{l}\text { Liver } \\
\text { cancer }\end{array}$ & yes & no & $\begin{array}{l}\text { Dose of mg PTX } \\
\text { equiv./kg }\end{array}$ & 1 \\
\hline 21 & $\begin{array}{l}\text { Integrin-assisted drug delivery of } \\
\text { nano-scaled polymer therapeutics } \\
\text { bearing paclitaxel }\end{array}$ & $\begin{array}{l}\text { Polyglutamic } \\
\text { acid } \\
\text { nanoparticles }\end{array}$ & $\begin{array}{l}\text { Breast } \\
\text { cancer }\end{array}$ & yes & no & $\begin{array}{l}\text { Dose of } 15 \mathrm{mg} \text { PTX } \\
\text { equiv./kg, every day for } \\
5 \text { days }\end{array}$ & 5 \\
\hline 22 & $\begin{array}{l}\text { Preclinical efficacy studies of a novel } \\
\text { nanoparticle-based } \\
\text { formulation of paclitaxel that out- } \\
\text { performs Abraxane }\end{array}$ & $\begin{array}{c}\text { PGG } \\
\text { nanoparticles }\end{array}$ & $\begin{array}{l}\text { Lung, } \\
\text { ovarian } \\
\text { and } \\
\text { melanoma }\end{array}$ & yes & yes & $\begin{array}{l}\text { Ovarian (single } \\
\text { dosing): } 300 \mathrm{mg} \text { PTX } \\
\text { equiv./kg of PGG-PTX } \\
\text { and } 200 \mathrm{mg} \text { PTX } \\
\text { equiv./kg of Abraxane } \\
\text { Melanoma (single } \\
\text { dosing): } 350 \mathrm{mg} \text { PTX } \\
\text { equiv./kg of PGG-PTX } \\
\text { and } 150 \mathrm{mg} \text { PTX } \\
\text { equiv./kg of Abraxane } \\
\text { Lung (single dosing): } \\
300 \text { mg PTX equiv./kg } \\
\text { of PGG-PTX and } 250 \\
\text { mg PTX equiv./kg of } \\
\text { Abraxane } \\
\text { Lung (multiple dosing): } \\
140 \text { mg PTX equiv./kg } \\
\text { of PGG-PTX and } 40 \\
\text { mg PTX equiv./kg of } \\
\text { Abraxane, given } \\
\text { weekly three times }\end{array}$ & 1 or 3 \\
\hline 23 & $\begin{array}{l}\text { High tolerated paclitaxel nano- } \\
\text { formulation delivered by poly (lactic- } \\
\text { co-glycolic acid)-g-dextran micelles } \\
\text { to efficient cancer therapy }\end{array}$ & $\begin{array}{l}\text { PLGA-dextran } \\
\text { nanoparticles }\end{array}$ & $\begin{array}{l}\text { Ovarian } \\
\text { cancer }\end{array}$ & yes & no & $\begin{array}{l}\text { Taxol (12.5 mg PTX } \\
\text { equiv./kg), Dex- } \\
\text { PLGA/PTX (6.25, } 12.5 \\
\text { and } 25 \mathrm{mg} \text { PTX }\end{array}$ & 3 \\
\hline
\end{tabular}




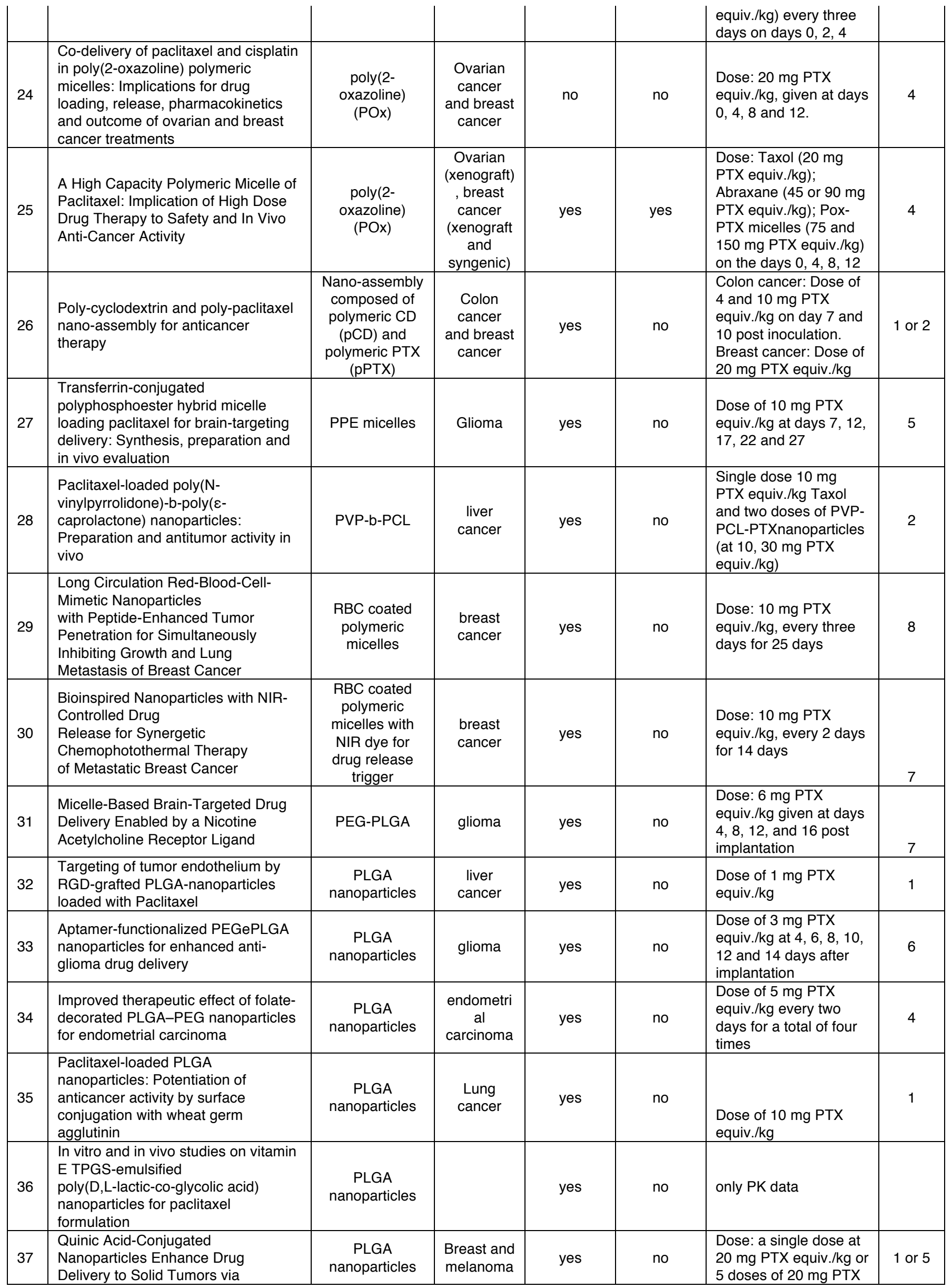




\begin{tabular}{|c|c|c|c|c|c|c|c|}
\hline & $\begin{array}{l}\text { Interactions with Endothelial } \\
\text { Selectins }\end{array}$ & & & & & $\begin{array}{l}\text { equiv./kg every } 3 \text { days } \\
\text { over } 2 \text { weeks. }\end{array}$ & \\
\hline 38 & $\begin{array}{l}\text { An Imagable and Photothermal } \\
\text { "Abraxane-Like" Nanodrug } \\
\text { for Combination Cancer Therapy to } \\
\text { Treat Subcutaneous } \\
\text { and Metastatic Breast Tumors }\end{array}$ & $\begin{array}{l}\text { theranostic } \\
\text { "Abraxane" } \\
\text { formulation } \\
\text { composed of } \\
\text { HSA, PTX, and } \\
\text { indocyanine } \\
\text { green (ICG) }\end{array}$ & $\begin{array}{l}\text { breast } \\
\text { cancer }\end{array}$ & no & yes & $\begin{array}{l}\text { Dose: a single dose at } \\
\sim 13 \mathrm{mg} \text { PTX equiv. } / \mathrm{kg}\end{array}$ & 1 \\
\hline 39 & $\begin{array}{l}\text { A Comparative In Vivo Study of } \\
\text { Albumin-Coated Paclitaxel } \\
\text { Nanocrystals and Abraxane }\end{array}$ & $\begin{array}{l}\text { PTX } \\
\text { nanocrystals } \\
\text { coated with } \\
\text { albumin }\end{array}$ & Melanoma & no & yes & $\begin{array}{l}\text { Dose: } 30 \mathrm{mg} \text { PTX } \\
\text { equiv./kg every } 3 \text { days } \\
\text { for five times (up to day } \\
\text { 15) }\end{array}$ & 5 \\
\hline 40 & $\begin{array}{l}\text { Targeting of albumin-embedded } \\
\text { paclitaxel nanoparticles to } \\
\text { tumors }\end{array}$ & $\begin{array}{l}\text { Abraxane } \\
\text { modified to } \\
\text { include a } \\
\text { targeting } \\
\text { peptide }\end{array}$ & $\begin{array}{l}\text { Breast } \\
\text { cancer }\end{array}$ & no & yes & $\begin{array}{l}\text { Dose: } 3 \mathrm{mg} \text { PTX } \\
\text { equiv. } / \mathrm{kg} / \mathrm{day} \text {, four } \\
\text { times a week for } 3 \\
\text { weeks }\end{array}$ & 12 \\
\hline 41 & $\begin{array}{l}\text { HFT-T, a Targeting Nanoparticle, } \\
\text { Enhances Specific Delivery of } \\
\text { Paclitaxel to Folate Receptor-Positive } \\
\text { Tumors }\end{array}$ & $\begin{array}{l}\text { Heparin-folic } \\
\text { acid-paclitaxel }\end{array}$ & $\begin{array}{l}\text { Head and } \\
\text { neck } \\
\text { cancer }\end{array}$ & yes & no & $\begin{array}{l}\text { Dose: } 20 \mathrm{mg} \text { PTX } \\
\text { equiv. } / \mathrm{kg} \text {, given at days } \\
1,7,13,20 \text {, and } 27\end{array}$ & 5 \\
\hline 42 & $\begin{array}{l}\text { A Paclitaxel-Loaded Recombinant } \\
\text { Polypeptide Nanoparticle } \\
\text { Outperforms Abraxane in Multiple } \\
\text { Murine Cancer Models }\end{array}$ & $\begin{array}{l}\text { Elastin-like- } \\
\text { polypeptides } \\
(\text { ELP)-PTX }\end{array}$ & $\begin{array}{l}\text { Breast and } \\
\text { prostate } \\
\text { cancer }\end{array}$ & yes & yes & $\begin{array}{l}\text { Dose: A single injection } \\
\text { of PTX (at } 25 \mathrm{mg} \text { PTX } \\
\text { equiv. } / \mathrm{kg}) \text { and } \\
\text { Abraxane ( } 50 \mathrm{mg} \text { PTX } \\
\text { equiv. } / \mathrm{kg} \text { ) and ELP- } \\
\text { PTX }(50 \mathrm{mg} \text { PTX } \\
\text { equiv. } / \mathrm{kg})\end{array}$ & 1 \\
\hline
\end{tabular}




\section{Materials and Methods}

\section{A. Materials}

Cloning and protein expression: pET-24+ plasmid was purchased from Novagen Inc (Madison, WI). Custom oligonucleotides were synthesized by Integrated DNA Technologies Inc (Coralville, IA). DNA mini-prep and gel purification kits were purchased from Qiagen Inc. (Germantown, MD). Chemically competent Escherichia coli EB5-alpha and BL21 (DE3) cells, restriction enzymes, T4 DNA ligase, Quick ligase, and calf intestinal phosphate (CIP) were purchased from New England Biolabs (Ipswich, MA). Bacterial cultures were grown in 2XYT media that contains sodium chloride (5 $\mathrm{g} \mathrm{L}^{-1}$; Alfa Aesar, Ward Hill, MA), tryptone (16 g L-1, Becton, Dickinson and Co., Franklin Lakes, NJ), and yeast extract (10 g L ${ }^{-1}$, Becton, Dickinson and Co., Franklin Lakes, NJ). Kanamycin sulfate was purchased from EMD Millipore (Billerica, MA). Protein expression was induced with isopropyl $\beta$-d-1-thiogalactopyranoside (IPTG) from Gold Biotechnology (St. Louis, MO). All salts used for protein purification were purchased from Alfa Aesar (Ward Hill, MA). Tris(2-carboxyethyl)phosphine (TCEP) hydrochloride was purchased from Biosynth International (Itasca, IL). Detoxi-Gel resin was purchased from Thermo Fisher Scientific (Waltham, MA). AnykD TGX Stain-Free gels, Protein molecular weight marker (Precision Plus Protein unstained standards), and Laemmli's sample buffer were purchased from Bio-Rad Laboratories (Hercules, CA).

Paclitaxel conjugation: Paclitaxel was purchased from Ark Pharm (Arlington Heights, IL), levulinic acid was purchased from TCI America (Portland, OR), 4-(dimethylamino)pyridine (DMAP) was purchased from Alfa Aesar (Haverhill, MA), and N,N'-dicyclohexylcarbodiimide was purchased from Sigma Aldrich (St. Louis, MO). N-E-maleimidocaproic acid hydrazide (EMCH) was purchased from Thermo Fisher Scientific (Hampton, MA), and t.h.e. ${ }^{\circledR}$ Desiccant (Indicating) 8\% and Amicon Ultra-15 Amicon ultrafiltration spin columns (10 kDa molecular weight cutoff (MWCO)) were purchased from EMD Millipore (Billerica, MA). TLC silica plate $(25 \times 75 \mathrm{~mm})$ was purchased from Agela Technologies (Torrance, CA), and silica gel (70-200 mesh) was purchased from Alfa Aesar (Haverhill, MA). Anhydrous methanol and dimethylformamide (DMF) were purchased from Sigma Aldrich (St. Louis, MO), and 
chloroform, ethyl ether, triethylamine, and acetonitrile were purchased from VWR BDH Analytical Chemicals (Radnor, PA).

Cell lines: Human cell line PC-3M-luc-C6 was purchased from Perkin Elmer (Hopkinton, MA), HT-29 cells were purchased from ATCC, and patient derived colon cancer cell lines CRC247, CRC12x and CRC119 cells were obtained from David Hsu (Duke University) and passaged less than 10 times. MDAMB-231 cells were obtained from Duke Cell Culture Facility, a repository of ATCC cell lines that are available to Duke University researchers. All the cell lines were authenticated by the DNA Analysis Sequencing facility at Duke University using Short Tandem Repeat (STR) DNA profiling. Cell lines used in the animal studies were verified to be murine pathogen free following IMPACT III murine pathogen analysis by IDEXX BioResearch (Columbia, MO). PC3 cells were cultured in Gibco MEM media modified with Earle's salts, L-glutamine (Waltham, MA) and supplemented with 10\% heat inactivated-fetal bovine serum (FBS), $0.1 \mathrm{mM}$ non-essential amino acids, $1 \mathrm{mM}$ sodium pyruvate, and 1\% penicillin/streptomycin. MDA-MB-231 cells were cultured in minimum essential medium Eagle (MEME) with Earle's salts, Lglutamine, and sodium bicarbonate (Sigma Aldrich, St. Louis, MO) supplemented with 10\% FBS, 1mM sodium pyruvate, and $0.1 \mathrm{mM}$ non-essential amino acids. HT-29 cells were cultured in McCoy's media with 10\% FBS and 1\% penicillin/streptomycin. Patient derived cell lines, CRC12x, CRC247, and CRC119 were cultured in Roswell Park Memorial Institute (RPMI) 1640 medium supplemented with 10\% FBS and 1\% penicillin/streptomycin. Unless noted, all cell culture reagents and FBS were purchased from Gibco (Waltham, MA). All cells were grown at $37{ }^{\circ} \mathrm{C}, 5 \% \mathrm{CO}_{2}$ atmosphere, and were passaged every 2-3 days with $0.05 \%$ trypsin/EDTA.

Animal models: Five to six weeks old athymic BALB/c nude mice were purchased from Duke University Division of Laboratory Animal Resources and were housed in the Duke Cancer Center Isolation Facility. Mice were housed in a room maintained on a $12 \mathrm{~h}$ light and dark cycle with ad libitum access to food and water. Mice were fed standard rodent diet (LabDiet 5001) unless otherwise indicated. All animal study was 
done in accordance with the NIH Guide for the Care and Use of Laboratory Animals under protocols approved by the Duke Institutional Animal Care and Use Committee (IACUC).

\section{B. Gene synthesis}

Genes encoding the ELP sequence SKGPG-(VPGXG) ${ }_{160}$ with the guest residue $\mathrm{X}=\mathrm{G}$ :A in a 1:1 ratio, and the ZIPP sequence SKGPG-(VPKEG) 120 were synthesized using a technique called recursive directional ligation by plasmid reconstruction (Pre-RDL), as described previously. ${ }^{1,2}$ Both ELP and ZIPP were further modified to include a drug-attachment-domain (DAD) at the C-terminus. The DAD sequence, (VPGAGVPG $\underline{\mathbf{C G}})_{8}$, consists of eight cysteine residues that have orthogonal thiol groups for chemical conjugation of thiol-reactive small molecules. The spacing between Cys — the drug attachment site-was designed to be nine amino acids such that steric hindrance from the bulky PTX molecules can be avoided, to enable multiple copies of PTX to be attached to a polypeptide chain. The dipeptide WP was also appended after the DAD to enable facile quantification of protein concentration by UV-vis spectroscopy. The lengths of ELPs and ZIPPs were chosen such that their molecular weight (MW) was slightly above the renal threshold of $60 \mathrm{kDa}$, so that any differences in their PK that are controlled by their sequence would become readily apparent. ${ }^{3,4}$ The final sequence for both ELP and ZIPP are provided in Table S1.

\section{Protein expression and purification}

ZIPPs and ELPs were expressed from a modified $\mathrm{pET}-24+$ expression vector $^{5}$ that was transformed into the E. coli strain BL21(DE3). $50 \mathrm{~mL}$ cultures of E. coli, harboring plasmids encoding ELP or ZIPP were inoculated from frozen DMSO stocks and grown at $37{ }^{\circ} \mathrm{C}$. After $16 \mathrm{~h}$, each $50 \mathrm{~mL}$ culture was used to inoculate three $1 \mathrm{~L}$ flasks of 2 XYT media supplemented with $45 \mu \mathrm{g} \mathrm{mL} \mathrm{m}^{-1}$ kanamycin. For ZIPP-DAD constructs, each $1 \mathrm{~L}$ flask was then grown at $25^{\circ} \mathrm{C}$ in a shaker incubator at $200 \mathrm{rpm}$ for $8 \mathrm{~h}$, at which time the cultures were induced with $1 \mathrm{mM}$ IPTG and grown for an additional $16 \mathrm{~h}$ at $16^{\circ} \mathrm{C}$. ELP-DAD constructs were grown at $37{ }^{\circ} \mathrm{C}$. Cells were harvested by centrifugation at $3000 \mathrm{xg}$ for $10 \mathrm{~min}$ at $4{ }^{\circ} \mathrm{C}$ and resuspended in $20 \mathrm{~mL}$ of cold PBS, which was followed by the cell lysis step. Cells were lysed via sonication (QSonica, 
Newtown, CT) on ice with $10 \mathrm{~s}$ on and $40 \mathrm{~s}$ off pulses for a total of $3 \mathrm{~min}$. Nucleic acids and cellular debris were precipitated by adding polyethylenimine (10\%; MP Biomedical) and centrifugation at 20,000 x $\mathrm{g}$ for 15 min at $4{ }^{\circ} \mathrm{C}$. After removal of nucleic acids and cellular debris, ZIPPs and ELPs were purified from the soluble fraction of the cell lysate through four rounds of inverse transition cycling, as previously described with minor modifications..$^{2,6,7}$ The supernatant was heated to $60^{\circ} \mathrm{C}$ for $10 \mathrm{~min}$ to trigger phase separation of the ELP-DAD and ZIPP-DAD and precipitation of contaminating proteins. This was followed by a cooling step in which the solution was placed on ice for 10 mins to allow ELP-DAD or ZIPP-DAD to re-dissolve while the contaminating proteins remain insoluble. Insoluble proteins were then precipitated by centrifugation at $20,000 \mathrm{xg}$ for $10 \mathrm{~min}$ at $4{ }^{\circ} \mathrm{C}$. This process was followed by salt-triggered phase separation at $37^{\circ} \mathrm{C}$ by the addition of $3 \mathrm{M}$ sodium chloride for the ELP-DAD or a combination of $3 \mathrm{M}$ sodium chloride and $2 \mathrm{M}$ ammonium sulfate for ZIPP-DAD, followed by centrifugation at 20,000 x g for $15 \mathrm{~min}$ at $37^{\circ} \mathrm{C}$ to obtain the ELP or ZIPP pellet. The pellet was resuspended in $50 \mathrm{mM}$ TCEP (pH 7), followed by a centrifugation step at $20,000 \mathrm{xg} 4^{\circ} \mathrm{C}$ for $10 \mathrm{~min}$ to remove any insoluble matter. These steps, starting with incubation at $60^{\circ} \mathrm{C}$, were repeated three more times, until a single band corresponding to the $\mathrm{MW}$ of the construct was observed in the SDS-PAGE gel. For animal experiments, endotoxin was removed using a Detoxi-Gel resin following the protocol supplied with the resin. Purity of the protein was assessed by SDSPAGE at $180 \mathrm{~V}$ for $40 \mathrm{~min}$ on an AnyKD TGX Stain-Free gel. The gel was then visualized using a ChemiDoc MP imager (Bio-Rad). Protein yield was determined gravimetrically after two rounds of dialysis into nanopure water and lyophilization for $72 \mathrm{~h}$.

\section{Intravenous pharmacokinetics of ZIPP-DAD and ELP-DAD}

The PK of ELP-DAD and ZIPP-DAD were investigated in vivo by radiolabeling. A separate construct with a single tyrosine residue appended at the C-terminus of the polypeptides after the DAD segment was made for site-specific radiolabeling (Table S1). Radiolabeling was carried out in a similar manner as previously described. ${ }^{8,9}$ Briefly, $100 \mu \mathrm{L}$ of ELP-DAD or ZIPP-DAD at $300 \mu \mathrm{M}$ was added to a pre-coated IODO-Gen tube with $2 \mathrm{mCi}\left[{ }^{131} \mathrm{I}\right] \mathrm{Na}$ on ice and incubated for $15 \mathrm{~min}$. A ZebaSpin desalting column (Thermo Fisher 
Scientific, Waltham, MA) was used to purify the reaction mixture. Mice were given $0.4 \mathrm{wt} \%$ potassium iodide water a week before injection to prevent accumulation of the radionuclide in the thyroid. ${ }^{131}$ I labeled samples were diluted with unlabeled polypeptide to have a radioactivity of $9.5 \mu \mathrm{Ci}$ prior to injection. 200 $\mu \mathrm{L}$ of $9.5 \mu \mathrm{Ci}{ }^{131} \mathrm{I}$ polypeptides at $300 \mu \mathrm{M}$ concentration was then injected $i . v$. via tail vein injection into nude mice. $10 \mu \mathrm{L}$ of blood was collected from the tail vein at $40 \mathrm{~s}, 30 \mathrm{~min}, 2 \mathrm{~h}, 4.5 \mathrm{~h}, 8 \mathrm{~h}, 24 \mathrm{~h}, 48 \mathrm{~h}$, and $72 \mathrm{~h}$ into tubes containing $100 \mu \mathrm{L}$ of heparin in PBS (1000 $\left.\mathrm{U} \mathrm{mL}^{-1}\right) .{ }^{131} \mathrm{I}$ labeled samples were aliquoted at different concentrations at the time of injection to create a standard curve (Fig. S9A). The amount of polypeptide in circulation was determined by measuring ${ }^{131} \mathrm{I}$ activity with an automated gamma counter (LKB-Wallac) in counts per minute (CPM).

\section{E. Intravenous pharmacokinetics of ZIPP-Cy5 and ELP-Cy5 nanoparticles}

Preparation of Cy5 labeled micelles: $50 \mathrm{mg}$ of ZIPP-DAD and ELP-DAD were resuspended in $1 \mathrm{ml}$ of sodium phosphate buffer ( $\mathrm{pH} 7.4$ ) with $1 \mathrm{ml}$ of $100 \mathrm{mM}$ TCEP (pH 7.4) for $1 \mathrm{~h}$ at room temperature. 20 molar equivalents of Cy5-maleimide (Lumiprobe, Hunt Valley, MD) dissolved at $100 \mathrm{mg} \mathrm{mL}^{-1}$ in DMSO was added to the polypeptide solution, and the conjugation reaction was allowed to proceed for $24 \mathrm{~h}$ at 4 ${ }^{\circ} \mathrm{C}$. Excess unreacted dye was removed by passing the reaction mixture through Sephadex G-25 PD 10 desalting column (GE Healthcare, Pittsburgh, PA), followed by buffer exchange with 75\% PBS and $25 \%$ acetonitrile by centrifugal ultrafiltration (Amicon Ultra-15, $10 \mathrm{kDa} \mathrm{MWCO}$ ). The labeled samples were finally buffer exchanged into Milli-Q water and then lyophilized (Labconco FreeZone, Kansas City, MO). The labeling efficiency was determined gravimetrically by weighing the samples for polypeptide concentration and then resuspending it into $1 \mathrm{x}$ PBS to measure Cy5 concentration using UV-vis spectrophotometry (NanoDrop 1000, Thermo Fisher, Waltham, MA), using absorbance at $646 \mathrm{~nm}$ and $\varepsilon=$ $250000 \mathrm{~cm}^{-1} \mathrm{M}^{-1}$ for the Cy5 fluorophore. ${ }^{10}$

Intravenous pharmacokinetics of ELP and ZIPP micelles: Athymic nude mice were administered with 10 $\mu \mathrm{M}$ Cy5 labeled micelles via tail vein injection. $10 \mu \mathrm{L}$ blood samples were collected into tubes with 100 
$\mu \mathrm{L}$ of heparin at various time points after injection and centrifuged at $5000 \mathrm{x} \mathrm{g}, 5 \mathrm{~min}, 4{ }^{\circ} \mathrm{C}$ to remove red blood cells. $50 \mu \mathrm{L}$ of the supernatant was loaded into a clear bottom 384 well plate (Corning, Corning NY). The plate was then read on a Typhoon 9410 Variable Mode Imager (GE Healthcare, Pittsburgh, PA) using the following settings: 450 PMT, $3 \mathrm{~mm}$ focal length. ${ }^{11}$ The amount of polypeptide remaining in circulation was calculated using a standard curve for Cy5 (Fig. S9B). Blood concentration versus time data was analyzed with a standard two compartment PK model to determine PK parameters. ${ }^{12}$ The elimination halflife $\left(t_{1 / 2 \beta}\right)$ was determined by calculating the slope of the linear regression fit to the elimination portion of the log concentration vs. time curve. The area under the curve (AUC) was calculated using the trapezoidal rule by GraphPad Prism 6 software $\left(\right.$ La Jolla, CA). The $\mathrm{C}_{\mathrm{o}}($ serum concentration at time $=0)$ was calculated by extrapolating a line through the early time points ( $40 \mathrm{~s}$ to $45 \mathrm{~min}$ range). The volume of distribution $\left(\mathrm{V}_{\mathrm{D}}\right)$ which reflects the degree of extravascular tissues and organs distribution was calculated as $V_{D}=($ dose injected i.v.)/ $\left(\mathrm{C}_{\mathrm{o}}\right)$. The clearance of the polypeptides from systemic circulation (CL) was calculated as $($ dose $\mathrm{x}$ F)/AUC, where F (bioavailability) $=1$ for $i . v$. bolus injection.

\section{F. Conjugation of PTX with ELP and ZIPP}

PTX conjugation was carried out by a multi-step reaction as previously published. ${ }^{13}$ Briefly, PTX was functionalized by modifying its 2'-OH group with levulinic acid (Lev). ${ }^{14}$ Activated PTX was then conjugated to the thiol groups in the Cys-rich DAD domain of the ZIPP or ELP through an acid-labile hydrazone moiety via an EMCH linker with a terminal maleimide moiety, which reacts with thiol groups to form a stable carbon-sulfur bond. ${ }^{15}$ For ZIPP-PTX conjugation, 6 M Guanidium Hydrochloride (pH 7) was added to a 55:45 (v/v) water and DMF mixture to avoid precipitation of the ZIPP and PTX-Lev-EMCH. After $24 \mathrm{~h}$, excess unreacted PTX-Lev-EMCH was purified by diluting the reaction mixture into $25 \%$ acetonitrile in PBS, followed by repeated centrifugal ultrafiltration (Amicon Ultra-15, MWCO: 10 kDa). After the final ultrafiltration step, the samples were buffer exchanged into ultrapure water with ammonium bicarbonate ( $\mathrm{pH}$ 7.4), followed by lyophilization. Purity of the drug conjugate was evaluated using size 
exclusion chromatography (SEC). Samples were run on a Shodex OHPak KB-904 SEC column on a Shimadzu Prominence High Performance Liquid Chromatography (HPLC) system with an isocratic flow of $0.5 \mathrm{~mL} \mathrm{~min}^{-1}$ of $70 \% \mathrm{PBS}$ and $30 \%$ acetonitrile (Fig. S2A). The HPLC data was quantified using the integrated area under the peak at an absorbance of $228 \mathrm{~nm}$ that corresponds to the maximum absorbance of PTX. The conjugation ratio of PTX to ELP or ZIPP was determined by matrix-assisted laser desorption/ionization mass spectrometry (MALDI-MS) on a Bruker Autoflex Speed LRF MALDI-TOF System with $100 \mu \mathrm{M}$ of samples mixed with a saturated sinapinic acid matrix at a ratio of 1:5.2 $\mu 1$ of sample mixed in the matrix was deposited onto a ground steel target plate and dried in air at room temperature. All the spectra were calibrated against ProteoMass ${ }^{\mathrm{TM}}$ Aldolase (Sigma Aldrich, St. Louis, MO). The MW difference between free polypeptide and drug conjugated polypeptide was divided by the MW of PTX-LevEMCH (1150 Da) to calculate the number of PTX molecules conjugated per polypeptide chain (Fig. 2B).

\section{G. Dynamic light scattering}

Dynamic light scattering (DLS) was carried out to determine the hydrodynamic radius $\left(\mathrm{R}_{\mathrm{h}}\right)$ of both ZIPPPTX and ELP-PTX conjugates using a DynaPro temperature controlled microsampler (Wyatt Technology, Santa Barbara, CA). Samples were prepared at $25 \mu \mathrm{M}$ in PBS and filtered through $0.2 \mu \mathrm{m}$ Whatman Anotop sterile syringe filters (GE Healthcare Life Sciences, Pittsburgh, PA) into a quartz crystal cuvette (12 $\mu$, Wyatt Technology, Santa Barbara, CA). Five acquisitions were taken at $37^{\circ} \mathrm{C}$, and the data was analyzed with a regularization fit of the autocorrelation function.

\section{H. Determination of critical aggregation concentration (CAC)}

Fluorescence spectroscopy with pyrene was preformed to determine the critical aggregation concentration (CAC). In this assay, pyrene is used as a probe to calculate the local hydrophobicity. ${ }^{16} 12 \mathrm{mM}$ of a pyrene stock solution was first prepared in ethanol and sonicated for $10 \mathrm{~min}$ at room temperature. Then $1 \mu \mathrm{L}$ of the stock solution was added to $20 \mathrm{~mL}$ of PBS, followed by 10 min sonication. Both stock and pyrene-PBS 
solution were protected from the light during sample preparation. This pyrene solution in PBS was used to dissolve PTX micelles at various concentrations. The samples were then loaded into a cuvette and read using a Cary Eclipse fluorescence spectrometer equipped with a Xenon flash lamp (Varian Instruments, Palo Alto, CA) at Ex: 334nm and Em: 360-380nm. Pyrene has four fluorescence emission peaks; the intensity of the first peak $\left(\mathrm{I}_{370-373 \mathrm{~nm}}\right)$ and the third peak $\left(\mathrm{I}_{381-384 \mathrm{~nm}}\right)$ were measured. The ratio of the two peaks were calculated as a function of log micelle concentration. Two linear equations were fitted to the data and the intersection of these two lines was defined as the CAC (Fig. S2D).

\section{Static light scattering}

Static light scattering (SLS) of ZIPP-PTX and ELP-PTX conjugates was carried out on an ALV/CGS-3 goniometer system (Langen, Germany) of. Samples were prepared at $25 \mu \mathrm{M}$ in PBS and filtered through $0.2 \mu \mathrm{m}$ Whatman Anotop syringe filters into disposable borosilicate glass tubes $(10 \mathrm{~mm}$; Fisher Scientific, Pittsburgh, PA). SLS measurements were obtained for angles between $30-150^{\circ}$ at $5^{\circ}$ increments with each angle consisting of 3 runs of $5 \mathrm{~s}$ each at $37^{\circ} \mathrm{C}$. The radius of gyration $\left(\mathrm{R}_{\mathrm{g}}\right)$ and the average molecular weight of the particle $\left(\mathrm{M}_{\mathrm{w}}\right)$ were calculated from the slope and intercept of a partial Zimm plot using ALV STAT

software. $\mathrm{N}_{\mathrm{agg}}$ was determined by dividing the particle molecular weight by molecular weight of an individual chain with 2.5 molecules of conjugated PTX. The differential refractive index $\left(\mathrm{dn}^{\mathrm{dc}} \mathrm{c}^{-1}\right)$ was determined by measuring the refractive index of the ELP-PTX and ZIPP-PTX conjugate at five different concentrations at $37^{\circ} \mathrm{C}$ using an Abbemat 500 refractometer (Anton Paar, Graz, Austria) (Fig. S2B).

\section{J. Cryogenic transmission electron microscopy}

ZIPP-PTX and ELP-PTX conjugates were imaged by cryo-transmission electron microscopy (cryo-TEM) at Duke University's Shared Materials Instrumentation Facility. Lacey holey carbon grids (Ted Pella, Redding, CA) were glow discharged in a PELCO EasiGlow Cleaning System (Ted Pella, Redding, CA). A $3 \mu \mathrm{L}$ drop of $25 \mu \mathrm{M}$ sample was deposited onto the grid and flash frozen by plunging into liquid ethane 
using the Vitrobot Mark III (FEI, Eindhoven, Netherlands). Grids were then transferred under liquid nitrogen to a Gatan 626 cryoholder (GATAN Inc., Pleasanton, CA) and imaged on a FEI Tecnai G ${ }^{2}$ Twin TEM (FEI-Company, Eindhoven, the Netherlands). The average nanoparticle core radii were calculated from TEM images in ImageJ (National Institutes of Health, MD).

\section{K. pH dependent drug release}

Samples were first prepared in $100 \mathrm{mM}$ ammonium bicarbonate buffer at $\mathrm{pH}$ 7.4. These samples were then incubated at $37^{\circ} \mathrm{C}$ in two different $\mathrm{pH}$ buffers: $100 \mathrm{mM}$ sodium acetate $\mathrm{pH} 5.4$ (endosomal) and sodium phosphate $\mathrm{pH} 7.4$ at final polypeptide concentration of $1 \mathrm{mg} \mathrm{mL} \mathrm{mL}^{-1}$. Samples were incubated for specified times $-0 \mathrm{~m}, 5 \mathrm{~m}, 10 \mathrm{~m}, 30 \mathrm{~m}, 1 \mathrm{~h}, 2 \mathrm{~h}, 4 \mathrm{~h}, 6 \mathrm{~h}, 8 \mathrm{~h}$ and $24 \mathrm{~h}$ - and at each time point, PTX released from the polypeptides was quenched by dilution of samples in acetonitrile and phosphate buffer at $\mathrm{pH} 7.4$ such that the final acetonitrile concentration was $33 \%$ and the $\mathrm{pH}$ was greater than 7.0 to stop hydrolysis. The samples were frozen immediately on dry ice and, and the release of PTX and PTX-Lev was monitored the same day by LC-MS-MS with deuterated PTX (PTX-d5) as internal standard. LC-MS/MS system consisted of a Shimadzu 20A series LC system with an Applied Biosystems MDS Sciex 4000 QTrap tandem mass spectrometer with ESI (ESI-MS/MS) operated in MRM mode. $10 \mu \mathrm{L}$ of sample was mixed with $10 \mu \mathrm{L}$ of $1 \mu \mathrm{g} / \mathrm{mL}$ PTX-d5 (acetonitrile) and $100 \mu \mathrm{L}$ of $50 \mathrm{mM}$ Tris-HCl (pH 7.5). This was followed by liquidliquid extraction of analytes using $200 \mu \mathrm{L}$ of methyl tert-butyl ether. The $150 \mu \mathrm{L}$ of top (ether) layer was removed, and the solvent was evaporated with a gentle stream of nitrogen. The residue was reconstituted in $100 \mu \mathrm{L}$ of $80 \% 50 \mathrm{mM}$ Tris- $\mathrm{HCl}$ and $20 \%$ acetonitrile and $10 \mathrm{~L}$ of the sample was injected into LC-

MS/MS system. Column: Eclipse Plus C18 (Agilent) at $40{ }^{0} \mathrm{C}$; mobile phase A: $0.1 \%$ formic acid, $2 \%$ acetonitrile, in water; mobile phase B: acetonitrile. Gradient elution was used with: 0-1 min 5-95\% B, 1-2 $\min 95 \% \mathrm{~B}$, and 2-2.2 $\min 95-5 \% \mathrm{~B}$ with a total run time of 5 min. A known amount of pure PTX and PTXLev was also analyzed along with the samples to create a standard curve (Fig. S9C). Parent/daughter MS/MS ion transitions of PTX, PTX-Lev, and PTX-d5 were monitored as follows: PTX 854.3/285.7, PTX- 
Lev 952.5/383.6 and PTX-d5 859.3/290/7. A linear response was observed within the concentration range selected for the standard curve. Data for the release kinetics were fitted to an exponential one-phase decay model in GraphPad Prism v.7.0 software (GraphPad, San Diego, CA).

\section{In vitro cytotoxicity of PTX conjugate nanoparticles}

In vitro cytotoxicity was quantified using a Promega CellTiter-Glo luminescent cell viability kit (Promega, Madison, WI). 3 x $10^{3}$ cells (for MDA-MB-231) and 2 x 10³ cells (for PC3, HT-29, CRC119, CRC247 and CRC 12x) were seeded in $80 \mu \mathrm{L}$ of media in Greiner Bio-one white 96-well flat bottom cell culture plates (Cat no: 655098). The cells were allowed to adhere for 16-18 h before treatment with free PTX, Abraxane, ZIPP-PTX, and ELP-PTX at concentrations that ranged from sub-nanomolar to high micromolar. After 72 $\mathrm{h}$ of drug treatment, $15 \mu \mathrm{L}$ of CellTiter-Glo reagent was added to each well in the dark. Cells were incubated for $40 \mathrm{~min}$, and the luminescence was measured on a Victor ${ }^{3}$ microplate reader (Perkin Elmer; Waltham, MA). For each plate, cells treated with PBS were defined as $100 \%$ viable. The percentage of viable cells in drug treated wells was calculated by normalizing the luminescence reading from each treatment well to the luminescence of PBS treated cells. The $50 \%$ inhibitory concentration, $\mathrm{IC}_{50}$, was determined by fitting the data to a four-parameter logistic fit in GraphPad Prism (GraphPad, San Diego, CA).

\section{Cell cycle analysis}

$1.36 \times 10^{5} \mathrm{PC} 3$ cells were plated onto six-well plates in $3 \mathrm{~mL}$ complete media. The cells were allowed to grow for $16 \mathrm{~h}$ up to $40 \%$ confluency, at which point treatment was initiated with $10 \mathrm{nM}$ PTX, ZIPP-PTX, or ELP-PTX nanoparticles. The treatment was withdrawn after $24 \mathrm{~h}$ by replacing the media containing the drug with fresh media. The cells were allowed to grow for another $24 \mathrm{~h}$, and both floating and adherent cells were then harvested. Cell cycle analysis was done using a Propidiun Iodide flow cytometry kit (Abcam \# ab139418) following the manufacturer's protocol as follows: the cells were pelleted by centrifugation at $500 \mathrm{x} \mathrm{g}$ for $5 \mathrm{~min}$, and the cell pellet was resuspended in 1x PBS followed by centrifugation at $500 \mathrm{x} \mathrm{g}$ for 5 min. The cells were then fixed in $66 \%$ ice cold ethanol and PBS and incubated overnight at $4{ }^{\circ} \mathrm{C}$. The 
ethanol was then removed by pelleting the cells at $500 \mathrm{x}$ g for $5 \mathrm{~min}$ and washing with $1 \mathrm{x}$ PBS, followed by centrifugation at $500 \mathrm{x}$ g for $5 \mathrm{~min}$. Cells were resupended in $500 \mu \mathrm{L}$ of $1 \mathrm{x}$ Propidium Iodide and RNase solution and incubated in the dark for $30 \mathrm{~min}$ at $37^{\circ} \mathrm{C}$. The samples were then run on a BD FACS Canto II flow cytometer (BD, San Jose, CA), and the data were analyzed using FACS Diva Software. Appropriate FSV vs SSC gates were established to exclude cell debris and aggregates. Propidium iodide fluorescence was measured using $488 \mathrm{~nm}$ laser. A minimum of 10,000 events were gated per sample to determine the percentage of cells in each phase of the cell cycle.

\section{N. Fluorescent PTX micelle uptake}

For fluorescence visualization of PTX delivery with ELP and ZIPP nanoparticles, $3 \times 10^{4}$ PC3 cells were seeded in $100 \mu \mathrm{L}$ of complete media into four chambers of a $\mu$-Dish ${ }^{35 \mathrm{~mm}}$, culture-insert 4 well (1.5 coverslip, Ibidi, Madison, WI). Cells were allowed to adhere for $18 \mathrm{~h}$, after which the media was replaced with complete media containing $25 \mu \mathrm{M}$ of Cy5.5 labeled ELP-PTX or ZIPP-PTX micelles for either $4 \mathrm{~h}$ or $24 \mathrm{~h}$ at $37^{\circ} \mathrm{C}$. Following treatment, the media was removed, and the cells were washed with PBS, stained with 1x solution of CellMask ${ }^{\text {TM }}$ Green plasma membrane stain (Life Technologies, Carlsbad, CA) for 10 min at $37{ }^{\circ} \mathrm{C}$, and then washed with PBS. Next, the cells were incubated in $2 \mu \mathrm{M}$ Hoechst 33342 (Life Technologies, Carlsbad, CA) for $10 \mathrm{~min}$ at $37^{\circ} \mathrm{C}$ to stain the nuclei, followed by two PBS washes. Cells were maintained in fresh PBS on ice prior to imaging on an Andor Dragonfly spinning disk 500 series confocal on a LeicaDMi8 microscope (Oxford Instruments, Abingdon, UK) with a 63x water immersion objective and a Zyla 4.2 series camera. Cy5.5-labeled micelles were imaged with $640 \mathrm{~nm}$ excitation laser and 700/75 nm emission filter, Hoechst 33342 was imaged with a $405 \mathrm{~nm}$ excitation filter and 450/50 nm emission filter, and CellMask was imaged with a $488 \mathrm{~nm}$ excitation laser and 525/50 nm emission filter. Image analysis was done with ImageJ (National Institutes of Health, MD).

\section{O. Phamacokinetics of PTX and PTX-conjugate nanoparticles}

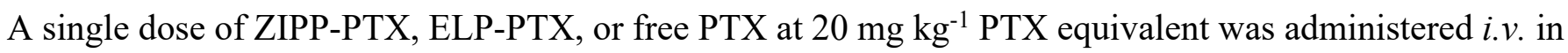


athymic nude mice. Over three days, $10 \mu \mathrm{L}$ of blood was collected from tail vein at different time points into $40 \mu \mathrm{L}$ of heparin $\left(1000 \mathrm{U} \mathrm{mL}^{-1}\right)$. As PTX is non-fluorescent, the concentration of paclitaxel and the conjugates in plasma was measured by LC-ESI-MS/MS instrument (Shimadzu 20A series LC system with Applied Biosystems MDS Sciex 4000 QTrap tandem mass spectrometer with ESI) as described above for $\mathrm{pH}$ release assay. The measurement of intact ZIPP-PTX and ELP-PTX conjugates was performed by measuring total PTX-Lev after acid hydrolysis, followed by subtraction of PTX-Lev measured before acid hydrolysis. Briefly, $5 \mu \mathrm{L}$ of plasma and $10 \mu \mathrm{L}$ of $0.2 \mu \mathrm{g} / \mathrm{mL}$ PTX-d5 (internal standard) and $100 \mu \mathrm{L}$ of $1 \%$ formic acid was added and extracted by $200 \mu \mathrm{L}$ methyl tert-butyl ether; after evaporation and reconstitution into mobile phase, $10 \mu \mathrm{L}$ was injected into LC-MS/MS. The concentration of PTX, PTX-Lev, and conjugates in the blood was calculated using a standard curve (Fig. S9D). To estimate the pharmacokinetic parameters, plasma concentration vs time data was analyzed using a two-compartment PK model as described earlier.

\section{P. Biodistribution of PTX and PTX-conjugate nanoparticles}

Preparation of Cy5.5 labeled PTX micelles: $100 \mathrm{mg}$ ZIPP-PTX and ELP-PTX micelles were resuspended in $2 \mathrm{~mL}$ of sodium phosphate buffer, $\mathrm{pH} 7.4$ with $2 \mathrm{~mL}$ of $100 \mathrm{mM}$ TCEP for $1 \mathrm{~h}$ at room temperature. 20 molar equivalents of Cy 5.5 maleimide (Lumiprobe, Hunt Valley, MD), dissolved at $100 \mathrm{mg} \mathrm{mL}^{-1}$ in DMSO was added to the micelle solution, and the conjugation reaction was allowed to proceed for $24 \mathrm{~h}$ at $4{ }^{\circ} \mathrm{C}$. Excess unreacted dye was removed by passing the reaction mixture through the Sephadex G-25 PD 10 desalting column (GE Healthcare, Pittsburgh, PA). The eluate from the PD-10 column was diluted to 75\% PBS and 25\% acetonitrile, followed by purification using centrifugal ultrafiltration with Amicon Ultra-15, $10 \mathrm{kDa}$ MWCO filter units. After the final centrifugation step, the labeled samples were buffer exchanged

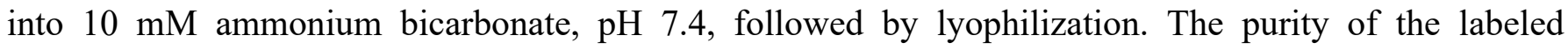
conjugates was assessed by SEC on a Shimadzu Prominence HPLC. Samples were run on a Shodex OHPak KB-904 SEC column with isocratic flow of $0.5 \mathrm{~mL} \mathrm{~min}^{-1}$ of $70 \% \mathrm{PBS}$ and $30 \%$ acetonitrile. The labeling efficiency was determined gravimetrically by weighing the samples for polypeptide concentration and then 
resuspending into PBS to measure Cy5.5 concentration using UV-vis spectrophotometry (NanoDrop 1000, Thermo Fisher, Waltham, MA) using absorbance at $684 \mathrm{~nm}$ and $\varepsilon=209000 \mathrm{~cm}^{-1} \mathrm{M}^{-1}$.

In vivo biodistribution: Male athymic nude mice (5-6 weeks old) were purchased from Duke University Division of Laboratory Animal Resources. $1 \times 10^{6}$ PC3 cells were inoculated in $50 \mu \mathrm{L}$ of phenol red free MEME media into the s.c. flank on the right hind leg of the mice. The mice were put on an irradiated 5V75 alfalfa-free rodent diet (LabDiets, St. Louis, MO) to reduce autofluorescence associated with chlorophyll that is present in regular rodent food. ${ }^{17}$ To quantify the accumulation of ELP-PTX and ZIPP-PTX micelles,

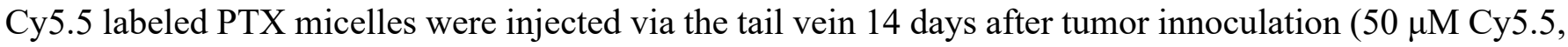
$582 \mu \mathrm{M}$ conjugates which corresponds to a dose of $20 \mathrm{mg} \mathrm{kg}^{-1} \mathrm{BW}$ PTX equiv.). Live mice were imaged on an IVIS Lumina instrument (Perkin Elmer) using 660/710 nm excitation and emission filters to visualzie and quantify the whole-animal biodistribution at the following post-injection time points: $2 \mathrm{~h}, 6 \mathrm{~h}, 8 \mathrm{~h}, 24$ h, $72 \mathrm{~h}, 120 \mathrm{~h}, 144 \mathrm{~h}$ and $168 \mathrm{~h}$. To quantify the amount of nanoparticle accumulation in the tumors over time, a region of interest (ROI) was drawn to cover the tumor area, and the fluorescence intensity in the ROI was calculated using Living Image Sotware (Perkin Elmer). This fluorescence intensity value was then normalized to the average tumor volume to account for any variability in tumor size. At $72 \mathrm{~h}(\mathrm{n}=2)$ and 168 $\mathrm{h}(\mathrm{n}=3)$ post-injection, a separate cohort of mice were euthanized, and the major organs (tumor, kidneys, liver, lungs, spleen, and heart) were harvested and fluorescently imaged ex vivo using IVIS Lumina and a Cy 5.5 filter set. The raw fluorescence value of each organ was then normalized to the sum of the fluoresence intensity for the all the organs that were imaged. ${ }^{18}$

Tumor accumulation of ELP-PTX and ZIPP-PTX nanoparticles was futher evaluated using fluorescence imaging of the tissue. Tumors harvested at $72 \mathrm{~h}$ and $168 \mathrm{~h}$ post-injection, and were immediately frozen in liquid nitrogen and embedded in optimal cutting temperature (OCT) compound. $10 \mu \mathrm{m}$ sections from the embedded tissue were cut using a Cryostat and placed on glass slides. The glass slides were then thawed for $20 \mathrm{~min}$ at room temperature and then stained in $1 \mu \mathrm{g} \mathrm{mL} \mathrm{m}^{-1}$ Hoechst 33342 solution. After $5 \mathrm{~min}$ of 
incubation in Hoechst solution, the slides were washed in PBS three times. $25 \mu \mathrm{L}$ of mounting media was used to apply the cover slip. The glass slides were then imaged using a Zeiss AxioSkop II with appropriate filter cubes for Cy5.5 and Hoechst 33342 with constant exposure times for each fluorophore and samples. ImageJ was used to analyze the images. Integrated density is reported rather than the mean fluorescence intensity in order to account for any discrepency in the size of the ROI between samples.

\section{Q. Maximum tolerated dose}

Athymic mice (6-8 weeks old) were used to evaluate the MTD of ZIPP-PTX. As the MTD of free PTX (at $25 \mathrm{mg} \mathrm{kg}^{-1}$ BW PTX equiv) and ELP-PTX ( $\geq 50 \mathrm{mg} \mathrm{kg}^{-1}$ BW PTX equiv) were already established

previously, ${ }^{13,19}$ a dose-escalation study was carried out to evaluate the MTD of ZIPP-PTX at doses of 50, 60, and $70 \mathrm{mg} \mathrm{kg}^{-1} \mathrm{BW}$ PTX equiv (n=3) by i.v. infusion using a syringe pump at $50 \mu \mathrm{L} \mathrm{min} \mathrm{m}^{-1}$ flow rate . Body weight was monitored as a surrogate for toxicity, for up to 10 days after the injection. The dose was considered "acceptable" if the weight loss was less than $15 \%$ of the initial body weight.

\section{R. Tumor regression and survival in mice}

$1 \times 10^{6} \mathrm{PC} 3$ cells in $50 \mu \mathrm{L}$ of Minimum Essential Medium (without Phenol red and serum) were inoculated into the s.c. flank on the right hind leg of male athymic nude mice (5-6 weeks old). 1 x $10^{6}$ HT-29 cells were inoculated in $50 \mu 1$ Minimum Essential Medium (without Phenol red and serum s.c. on the right hind leg of female athymic nude mice (5-6 weeks old). After the tumor reached a size of 75-100 $\mathrm{mm}^{3}$, mice were randomly divided into different treatment groups. Each treatment group received a single dose of a drug via tail vein injection. Tumor growth and BW was monitored 2-3 times a week, and tumor dimensions were measured using hand held digital calipers for 60 days after the treatment. Tumor volume was calculated using the equation: volume $\left(\mathrm{mm}^{3}\right)=\pi / 6 * \mathrm{~L}^{*} \mathrm{~W}^{2}$. Response to the treatments were evaluated by measuring the delay in tumor growth and survival, along with side effects including BW loss and poor body condition. Mice were sacrificed when the tumor volume reached $1500 \mathrm{~mm}^{3}$. All the mice experiencing BW loss right 
after dosing were given supportive care in the form of soft-food (wetted powdered food) and HydroGel ${ }^{\mathrm{TM}}$ $\left(\mathrm{ClearH}_{2} \mathrm{O}\right.$, Portland, Maine) and allowed to recover. Mice were euthanized if the BW loss was greater than $20 \%$ of original BW for three consecutive measurements and if there was no sign of recovery. Tumor growth rate was calculated by a linear regression of the growth phase (linear phase) of the tumor growth curve. The $\mathrm{T} / \mathrm{C}$ ratio, defined as the ratio of the mean tumor volume of treated mice $(\mathrm{T})$ to the mean tumor volume of control mice (C), was calculated to further evaluate the treatment efficacy. The T/C ratio was calculated on the last day when all mice in the control and treated groups had measurable tumor volumes.

\section{S. Data Analysis}

Data are presented as mean and standard error of the mean (SEM). PK parameters were compared between an ELP and ZIPP pair using Student's t-test. Biodistribution data between the two treatment groups was analyzed using Student's $t$-test correcting for multiple comparisons. Cell cycle data was analyzed using one-way ANOVA followed by Tukey's post-hoc test. Tumor growth data was analyzed using two-way ANOVA with Fisher's LSD multiple comparisons test to establish significance between different treatment groups on each day after treatment. Overall survival curves were made using the Kaplan-Meier method, and data were compared with the Gehan-Breslow-Wilcoxon test. The tumor growth rate was compared between groups by one-way ANOVA followed by Tukey's post-hoc test. All statistical analyses were performed using GraphPad Prism v.7.0 software (GraphPad, San Diego, CA). P $<0.05$ was considered as statistically significant. 


\section{Reference:}

(1) McDaniel, J. R.; MacKay, J. A.; Quiroz, F. G.; Chilkoti, A. Recursive Directional Ligation by Plasmid Reconstruction Allows Rapid and Seamless Cloning of Oligomeric Genes.

Biomacromolecules 2010, 11 (4), 944-952. https://doi.org/10.1021/bm901387t.

(2) Banskota, S.; Yousefpour, P.; Kirmani, N.; Li, X.; Chilkoti, A. Long Circulating Genetically Encoded Intrinsically Disordered Zwitterionic Polypeptides for Drug Delivery. Biomaterials 2019, 192. https://doi.org/10.1016/j.biomaterials.2018.11.012.

(3) Kontermann, R. E. Half-Life Modulating Strategies-An Introduction. In Therapeutic Proteins; Wiley-VCH Verlag GmbH \& Co. KGaA, 2012; pp 1-21. https://doi.org/10.1002/9783527644827.ch1.

(4) Ruggiero, A.; Villa, C. H.; Bander, E.; Rey, D. A.; Bergkvist, M.; Batt, C. A.; Manova-Todorova, K.; Deen, W. M.; Scheinberg, D. A.; McDevitt, M. R. Paradoxical Glomerular Filtration of Carbon Nanotubes. Proceedings of the National Academy of Sciences 2010, 107 (27), 12369-12374. https://doi.org/10.1073/pnas.0913667107.

(5) McDaniel, J. R.; MacKay, J. A.; Quiroz, F. G.; Chilkoti, A. Recursive Directional Ligation by Plasmid Reconstruction Allows Rapid and Seamless Cloning of Oligomeric Genes.

Biomacromolecules 2010, 11 (4), 944-952. https://doi.org/10.1021/bm901387t.

(6) MacEwan, S. R.; Hassouneh, W.; Chilkoti, A. Non-Chromatographic Purification of Recombinant Elastin-like Polypeptides and Their Fusions with Peptides and Proteins from $<\mathrm{em}>$ Escherichia Coli $</$ Em $>$. Journal of Visualized Experiments 2014, No. 88, e51583.

https://doi.org/10.3791/51583.

(7) Meyer, D. E.; Chilkoti, A. Purification of Recombinant Proteins by Fusion with ThermallyResponsive Polypeptides. Nature biotechnology 1999, 17 (11), 1112-1115. https://doi.org/10.1038/15100.

(8) Schaal, J. L.; Li, X.; Mastria, E.; Bhattacharyya, J.; Zalutsky, M. R.; Chilkoti, A.; Liu, W. Injectable Polypeptide Micelles That Form Radiation Crosslinked Hydrogels in Situ for Intratumoral Radiotherapy. Journal of controlled release : official journal of the Controlled Release Society 2016, 228, 58-66. https://doi.org/10.1016/j.jconrel.2016.02.040.

(9) Asai, D.; Xu, D.; Liu, W.; Garcia Quiroz, F.; Callahan, D. J.; Zalutsky, M. R.; Craig, S. L.; Chilkoti, A. Protein Polymer Hydrogels by in Situ, Rapid and Reversible Self-Gelation. Biomaterials 2012, 33 (21), 5451-5458. https://doi.org/10.1016/j.biomaterials.2012.03.083.

(10) Lumiprobe. Cyanine5 maleimide https://www.lumiprobe.com/p/cy5-maleimide.

(11) Bhattacharyya, J.; Weitzhandler, I.; Ho, S. B.; McDaniel, J. R.; Li, X.; Tang, L.; Liu, J.; Dewhirst, M.; Chilkoti, A. Encapsulating a Hydrophilic Chemotherapeutic into Rod-Like Nanoparticles of a Genetically Encoded Asymmetric Triblock Polypeptide Improves Its Efficacy. Advanced Functional Materials 2017, 1605421-n/a. https://doi.org/10.1002/adfm.201605421.

(12) Jambhekar, S.; Breen, P. Basic Pharmacokinetics; 2009.

(13) Bhattacharyya, J.; Bellucci, J. J.; Weitzhandler, I.; McDaniel, J. R.; Spasojevic, I.; Li, X.; Lin, C.C.; Chi, J.-T. A.; Chilkoti, A. A Paclitaxel-Loaded Recombinant Polypeptide Nanoparticle Outperforms Abraxane in Multiple Murine Cancer Models. Nature Communications 2015, 6 (1), 7939. https://doi.org/10.1038/ncomms8939.

(14) Etrych, T.; Sírová, M.; Starovoytova, L.; Ríhová, B.; Ulbrich, K. HPMA Copolymer Conjugates of Paclitaxel and Docetaxel with PH-Controlled Drug Release. Molecular pharmaceutics 2010, 7 (4), 1015-1026. https://doi.org/10.1021/mp100119f.

(15) Mackay, J. A.; Chen, M.; Mcdaniel, J. R.; Liu, W.; Andrew, J.; Chilkoti, A. Self-Assembling Chimeric Polypeptide-Doxorubicin Conjugate Nanoparticles That Abolish Tumors after a Single Injection. 2010, 8 (12), 993-999. https://doi.org/10.1038/nmat2569.Self-assembling.

(16) Zhao, C. Le; Winnik, M. A.; Riess, G.; Croucher, M. D. Fluorescence Probe Techniques Used to Study Micelle Formation in Water-Soluble Block Copolymers. Langmuir 1990, 6 (2), 514-516. https://doi.org/10.1021/la00092a038. 
(17) Williams, R. M.; Shah, J.; Tian, H. S.; Chen, X.; Geissmann, F.; Jaimes, E. A.; Heller, D. A. Selective Nanoparticle Targeting of the Renal Tubules. Hypertension 2018, 71 (1), 87-94. https://doi.org/10.1161/HYPERTENSIONAHA.117.09843.

(18) Namgung, R.; Mi Lee, Y.; Kim, J.; Jang, Y.; Lee, B. H.; Kim, I. S.; Sokkar, P.; Rhee, Y. M.; Hoffman, A. S.; Kim, W. J. Poly-Cyclodextrin and Poly-Paclitaxel Nano-Assembly for Anticancer Therapy. Nature Communications 2014, 5 (1), 3702. https://doi.org/10.1038/ncomms4702.

(19) Liu, J.; Pang, Y.; Bhattacharyya, J.; Liu, W.; Weitzhandler, I.; Li, X.; Chilkoti, A. Developing Precisely Defined Drug-Loaded Nanoparticles by Ring-Opening Polymerization of a Paclitaxel Prodrug. Advanced Healthcare Materials 2016, 1868-1873. https://doi.org/10.1002/adhm.201600230. 